\title{
Computational Aerodynamics of Shuttle Orbiter Damage Scenarios in Support of the Columbia Accident Investigation
}

\author{
Karen L. Bibb* \\ NASA Langley Research Center, Hampton, VA 23681 \\ Ramadas K. Prabhu ${ }^{\dagger}$ \\ Lockheed Martin Engineering and Sciences Company, Hampton, VA 23681
}

\begin{abstract}
In support of the Columbia Accident Investigation, inviscid computations of the aerodynamic characteristics for various Shuttle Orbiter damage scenarios were performed using the FELISA unstructured CFD solver. Computed delta aerodynamics were compared with the reconstructed delta aerodynamics in order to postulate a progression of damage through the flight trajectory. By performing computations at hypervelocity flight and $\mathbf{C F}_{4}$ tunnel conditions, a bridge was provided between wind tunnel testing in Langley's 20-Inch CF 4 facility and the flight environment experienced by Columbia during re-entry. The rapid modeling capability of the unstructured methodology allowed the computational effort to keep pace with the wind tunnel and, at times, guide the wind tunnel efforts. These computations provided a detailed view of the flowfield characteristics and the contribution of orbiter components (such as the vertical tail and wing) to aerodynamic forces and moments that were unavailable from wind tunnel testing. The damage scenarios are grouped into three categories. Initially, single and multiple missing full RCC panels were analyzed to determine the effect of damage location and magnitude on the aerodynamics. Next is a series of cases with progressive damage, increasing in severity, in the region of RCC panel 9. The final group is a set of wing leading edge and windward surface deformations that model possible structural deformation of the wing skin due to internal heating of the wing structure. By matching the aerodynamics from selected damage scenarios to the reconstructed flight aerodynamics, a progression of damage that is consistent with the flight data, debris forensics, and wind tunnel data is postulated.
\end{abstract}

\section{Nomenclature}

$b_{\text {ref }} \quad$ Reference length for rolling and yawing moments

$C \quad$ Force or moment coefficient, force normalized by $\frac{1}{2} \rho_{\infty} U_{\infty}^{2} S_{r e f}$, pitching moment by $\frac{1}{2} \rho_{\infty} U_{\infty}^{2} S_{r e f} c_{r e f}$, and rolling and yawing moments by $\frac{1}{2} \rho_{\infty} U_{\infty}^{2} S_{\text {ref }} b_{\text {ref }}$

$c_{\text {ref }} \quad$ Reference length for pitching moment

$M \quad$ Mach number

$S_{\text {ref }} \quad$ Reference area

$N$ number of mesh nodes

$T \quad$ Temperature

$U \quad$ Velocity

Subscripts

()$_{\infty} \quad$ Freestream

( $)_{A} \quad$ Axial force

()$_{i} \quad$ Generic force or moment

${ }^{*}$ Research Engineer, Aerothermodynamics Branch; Aerodynamics, Aerothermodynamics, and Acoustics Competency, MS 408A, Senior Member AIAA

${ }^{\dagger}$ Aerospace Engineer, Aerodynamics, Stuctures, and Materials Dept., Langley Program Office, NASA LaRC

This material is declared a work of the U.S. Government and is not subject to copyright protection in the United States.2004 
()$_{l} \quad$ Rolling moment

()$_{m} \quad$ Pitching moment

()$_{N} \quad$ Normal force

()$_{n} \quad$ Yawing moment

()$_{p} \quad$ Pressure

()$_{Y} \quad$ Side force

Symbols

$\alpha \quad$ Angle of attack

$\beta \quad$ Sideslip angle

$\Delta C \quad$ Delta force or moment coefficient, computed as in Eqn. 1 or 2

$\gamma \quad$ Ratio of specific heats

$\rho \quad$ Density

\section{Introduction}

ON February 1, 2003, the Orbiter Columbia broke up during the entry phase of its mission. Initially, the only information providing insight to the possible cause of this accident were the video footage of a large piece of foam hitting the left wing on ascent and the data from the Operational Instrumentation (OI) telemetry data received prior to loss of signal (LOS). The OI data showed that instrument failures had occurred in the left wheel well and that there was an off-nominal temperature rise in two bondline sensors located behind the Thermal Protection System (TPS) on the left side of the fuselage above the wing. The OI data also contained the accelerometer data, control surface positions, and flight attitude. Following the accident, the OI data was analyzed and possible scenarios that would fit the limited data were developed by the investigation team.

The Aerodynamics Team was then formed to reconstruct the flight aerodynamics in the form of delta aerodynamics, in order to understand how Columbia flew during its final minutes. The delta aerodynamics are simply the flight extracted aerodynamic force and moment coefficients for STS-107 minus the aerodynamics that the Orbiter Operational Aerodynamic Data Book (OADB ${ }^{1}$ ) predicted for the known control surface deflections, atmospheric conditions, and attitude $(\alpha$ and $\beta)$, and are defined in Eqn. 1 .

$$
\Delta C_{i}^{\text {reconstructed }}=C_{i}^{\text {flight extracted }}-C_{i}^{O A D B}
$$

where $C_{i}$ denotes one of the force or moment coefficients. The final reconstructed delta aerodynamics and the simplified simulation model for the STS107 flight from entry interface (EI) until loss of signal (LOS) is shown in Fig. 1. The only aerodynamic increments prior to EI+515 sec (8:52:44 EST, shown as 52:44 in Fig. 1) are due to bias, and are treated as zero. At EI+515, both delta rolling and yawing moments begin to trend negative. The yawing moment continues the negative trend, declining sharply just prior to LOS. At EI+602 (54:11), the rolling moment trend abruptly reverses sign, from an increasing negative to an increasing positive trend. All indications are that until just before LOS, Columbia's control system was able to compensate for alterations to the vehicle outer mold line via progressive damage. The reconstruction process, results, and limitations are discussed in detail in the Aerodynamics

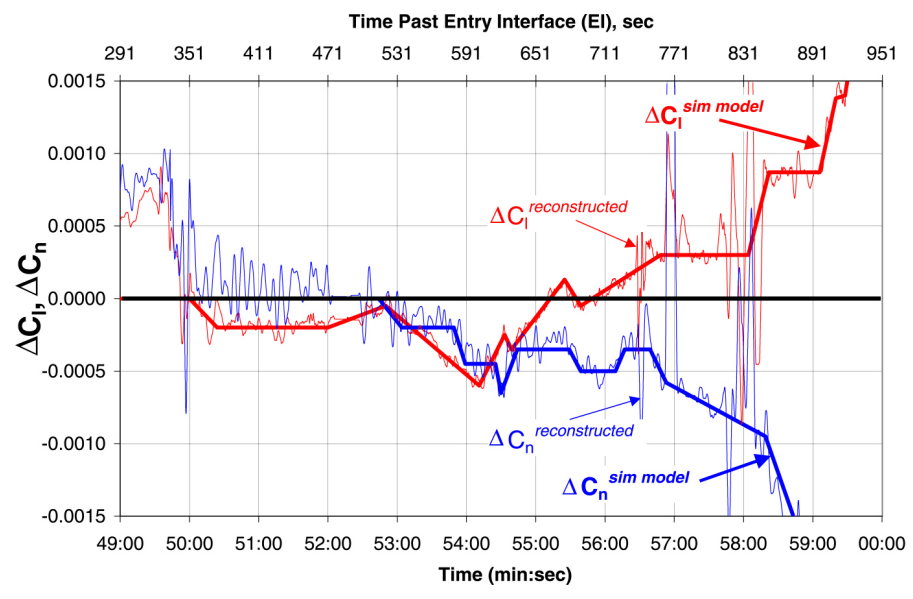

Figure 1. STS-107 delta aerodynamics, flight and simulation model Team's final report to the CAIB! ${ }^{2]}$

The team postulated that the delta aerodynamics from the flight data would be primarily due to the damage, that this delta aerodynamics could be simulated via wind tunnel measurements and CFD predictions, 
and that ultimately, a plausible progression of damage that correlated with the reconstructed delta aerodynamics could be developed. This premise guided the aerodynamic wind tunnel testing and computational simulation of Orbiter models with various left wing damage scenarios.

The Mach 6 air and the $\mathrm{CF}_{4}$ tunnels of the Langley Aerothermodynamics Laboratory ${ }^{3}$ were used for all of the experimental aerodynamic testing during the investigation $2|4|[5]$ The Mach 6 air facility was able to provide higher productivity than the $\mathrm{CF}_{4}$ facility, and was used in the initial phases of the investigation for rapid screening of damage scenarios from both an aerodynamic and aero-heating perspective. The important flow physics phenomena, such as flow separation and reattachment, boundary layer transition, and shockshock interactions, are all present in the perfect gas environment (post-normal shock ratio of specific heats, $\gamma \approx 1.4$ ) of the Mach 6 air tunnel, but the location and strengths of these features will be different for the hypervelocity flight environment due to the effects of flow chemistry. The $\mathrm{CF}_{4}$ tunnel,utilizing a test gas that is three times heavier than air, provides an environment similar (on the vehicle windside) to the flight environment with a thinner shock layer due to the decreased post normal-shock $\gamma(\approx 1.10)$ which is near the values within the Orbiter windward flow field at hypervelocity conditions. ${ }^{6}$ Based on previous studies performed in the $\mathrm{CF}_{4}$ tunnel, the conditions provided by the facility can be interpreted as simulating a flight condition in the range of Mach 13-18. While the ability of the $\mathrm{CF}_{4}$ tunnel to accurately simulate the leeside flow of the Orbiter at hypervelocity conditions has not been validated to the extent of the windward flow, the damage scenarios investigated have their origin on the wing leading edge and the windward surface, and thus the $\mathrm{CF}_{4}$ tunnel is expected to provide credible simulation of their effects. A more detailed discussion of the use of these facilities and their relationship to the flight environment can be found in Ref. 7 .

The Aerodynamics team performed simulations with three CFD codes. The majority of the computations were performed with FELISA, 89 an inviscid, unstructured CFD package that is primarily used for hypersonic flow corresponding to reacting flow (dissociation-recombination and ionization). The FeLISA methodology provided rapid meshing and parallelized solution capabilities that allowed the screening of a large number of damage scenarios and flow conditions over the course of the investigation. Additional aerodynamic methods (CART3D, OvERFLOW) were utilized for selected damage scenarios, ${ }^{2]}$ but were restricted to perfect gas air flows. The Aerothermodynamics team used viscous, structured grid codes (LAURA, GASP, USA) were utilized to provide detailed heating rates and flow visualization using chemical non-equilibrium models for a limited number of damage scenarios. ${ }^{2]}$ Development of the computational meshes for the viscous solvers took much longer than those for FELISA (weeks instead of a day), and the flow solutions were computationally more intense (days/weeks instead of hours); thus the limited aerodynamic results from the viscous solvers were used only as a check on the more abundant inviscid results. The FeLISA aerodynamic computations are the focus of the present work, and are presented as a series of "chronological" studies. Additional details about the computations can be found in Refs. 2 and 10 .

Within ten days after the accident, two cases had been run with simulated damage to panel 6 of the reinforced carbon-carbon (RCC) wing leading edge (WLE) in an effort to rapidly assess the flow physics of a WLE breach. These computations were the first evidence that damage to the WLE produced significant flow disturbances on the leeside fuselage, providing a credible explanation for the high heating rates recorded by the bondline sensors in this region, and led investigators in the wind tunnels to shift focus from windside boundary layer transition to the WLE. Subsequently, damage scenarios with various full RCC panels missing from the WLE were examined at both flight and wind tunnel conditions. Comparisons with wind tunnel data were critical in providing a link between the $\mathrm{CF}_{4}$ tunnel results and Columbia's flight environment, and established that the trends in the delta aerodynamics were not strongly dependent on either the flow condition or angle of attack. The delta aerodynamics showed that progressively removing more RCC panels was not consistent with the flight data showing a positive rolling moment trend after EI+600 sec. This led to the next group of damage scenarios, a series of progressive damage focused on the RCC panel 9 region, ranging from only a partial panel missing to the full panel with additional leeside material missing. Again, a positive rolling moment trend was not observed for these scenarios. The final group of damage scenarios focused on windward surface deformations to simulate structural deformation of the wing surface due to internal heating damage. A progression of damage that is consistent with the flight data, debris forensics, and tunnel data is postulated by combining the computational results from selected damage scenarios. 


\section{Methodologies}

The FELISA software package, consisting of unstructured mesh generation and inviscid flow solver capabilities, was used for the present work. This software has been used for aerodynamic analyses on most of NASA's recent planetary and reusable launch vehicles: Mars landers $\frac{11] 12]}{1} \mathrm{X}-33, \frac{9] 13}{\sqrt{13}} \mathrm{X}-34, \frac{14}{14} \mathrm{X}-37$, and the Shuttle Orbiter at high angles of attack! ${ }^{15}$

The geometry for the Orbiter was developed in GridTool,$\frac{16}{16}$ based on a 1997 CAD definition of the Orbiter. Surface meshes were generated with either the FELISA-SURFACE code or GridEx $\llbracket 17] 18]$ Volume meshes were generated with the FELISA-3D_MESH code. Creating a damage scenario geometry required 2-4 hours of preparation using GridTool, and generation of the meshes required 4-8 hours of computer time. Mesh sizes for the damage scenario cases ranged from 2.5 to 5.5 million nodes, with up to 30 million tetrahedral elements. Meshes for the $\mathrm{CF}_{4}$ conditions were smaller than for flight, as the shock stand-off distance was somewhat larger, which allowed for larger elements.

The FeLISA hypersonic flow solver ${ }^{9}$ was used for the present computations with perfect gas air, equilibrium air, and $\mathrm{CF}_{4}$ gas options. Computations at vehicle flight conditions utilized the equilibrium air model. Computations to match wind tunnel conditions utilized perfect gas air and $\mathrm{CF}_{4}$ gas, as appropriate. The FELISA solver is parallelized to provide rapid turn-around, and takes advantage of multiple computer architectures. For this investigation, the solver was run both on a local cluster of PCs with up to 24 processors, and on the NAS Origin 3000 system, chapman, with up to 64 processors. Wall clock time for obtaining a converged solution ranged from 8 to 24 hours, depending on mesh size and complexity of the damage scenario.

Convergence of the flow solutions was assessed by examining the time history of the residuals, the maximum and minimum enthalpies, and the aerodynamic forces and moments. The grid convergence was assessed for the undamaged baseline mesh only. Flow solution and grid convergence are discussed in more detail in the Results section.

The delta aerodynamics computation for wind tunnel data and CFD results is analogous to the flight reconstruction (Eqn. 1). All flow solutions were performed on a right-half vehicle, and the half-body loads computed. The full vehicle aerodynamic coefficients were then computed, using $S_{\text {ref }}=387,360 \mathrm{in}^{2}$, $c_{r e f}=474.7 \mathrm{in}$, and $b_{r e f}=936.7 \mathrm{in}$, and a moment reference point of $841.7 \mathrm{in}$ behind the nose and $38.5 \mathrm{in}$ above the centerline. For the damage scenario vehicle, this required transferring the computed loads to the left side of the vehicle (by making appropriate sign changes), and then adding the baseline results to give the aerodynamic coefficients for a vehicle with a damaged left side and an undamaged right side The damaged vehicle aerodynamics were then subtracted from the baseline aerodynamics to obtain the delta aerodynamic coefficients, as shown in Eqn. 2 .

$$
\Delta C_{i}=C_{i}^{\text {damaged }}-C_{i}^{\text {baseline }}
$$

When generating meshes for the damaged configurations, care was taken to have comparable mesh spacing in areas not affected by the damage, to mitigate the potential for corruption of the delta aerodynamics due to mesh differences. Experimental data used for comparison were taken from Refs. 2, 4 , and 5 .

\section{Geometry and Flow Conditions}

\section{A. Geometry}

At the time of the Columbia accident, a GridTool model of the Orbiter was available from a previous FELISA study ${ }^{15}$ This model was built from a structured grid developed at LaRC several years ago using a 1997 Orbiter CAD model. All of the FeLISA computations presented here use this model. Figure 2 shows a wireframe representation of the baseline geometry with the computational domain for the flight cases. For most cases only half-body simulations, which assume no flow across the vehicle centerline, were performed. The base of the Orbiter was not modeled (a typical simplification for hypersonic simulations when the primary interest is heating or aerodynamic screening). Since the investigation was primarily concerned with the delta aerodynamics, no attempt was made to model the body flap and elevons at STS-107 flight deflections; all control surfaces were set at zero degrees (trail position).

Geometry for the various damage configurations came from a variety of sources. The definition of the RCC and carrier panels along the WLE and the location of the wheel well doors was provided by JSC; CAD curves were then generated in an iges format for application to both computational and experimental

4 of 25 


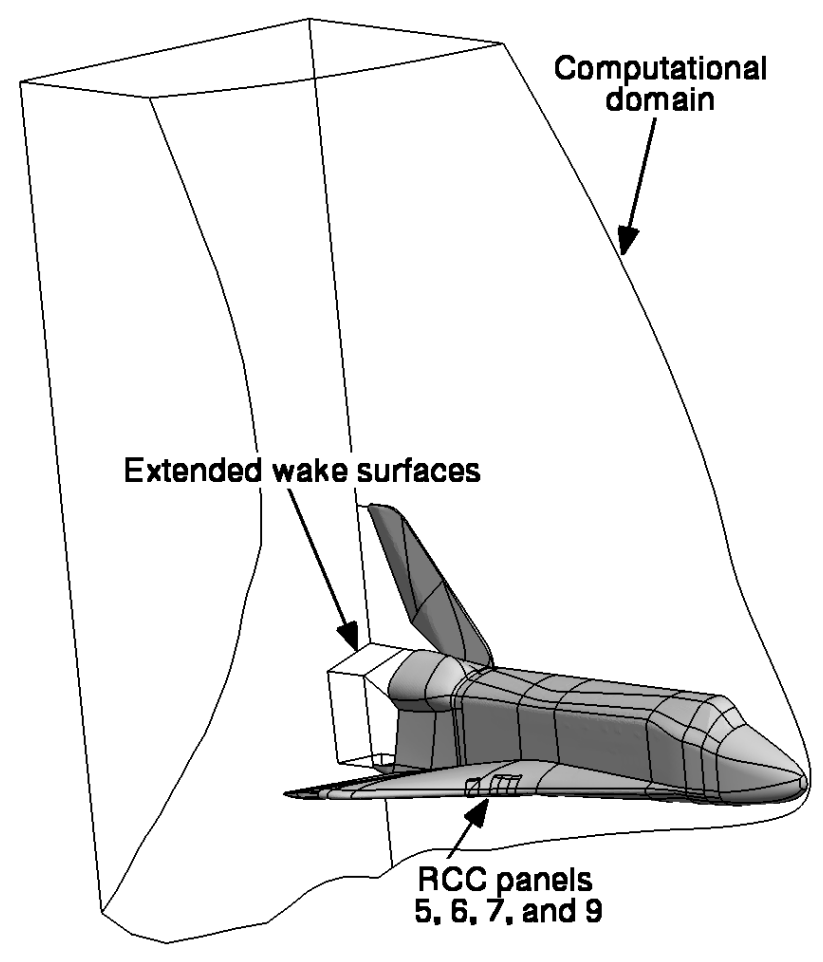

Figure 2. Baseline Orbiter geometry and computational domain

models. Partial panel damages and some of the WLE deformation geometry were created based on these curves and other Orbiter measurements. Geometry used to develop damage configurations are described in more detail in the Results section.

\section{B. Flow Conditions}

Initial computations on the missing panel 6 geometry were made using flow conditions from the STS-2 trajectory, as given in Table 1 These conditions had been utilized in numerous earlier studies validating predictions of Orbiter heating and aerodynamics $\frac{19}{20}$ and were in the range of the STS-107 trajectory prior to vehicle loss of signal. The flow conditions for the Mach 6 air and $\mathrm{CF}_{4}$ facilities are given in Table 2. Only the angle of attack and Mach number are required for the Mach 6 air perfect gas condition; as such, the freestream velocity, density and temperature are not given.

When the STS-107 trajectory became available, a set of points corresponding to specific events in the STS-107 entry timeline were selected to be used in all of the Table 1. STS-2 flow conditions for initial missing RCC panel 6 computations

\begin{tabular}{cccccc}
$\begin{array}{c}\text { STS-2 } \\
\text { Condition }\end{array}$ & $M_{\infty}$ & $\alpha$ & $\begin{array}{c}U_{\infty}, \\
f t / s\end{array}$ & $\begin{array}{c}\rho_{\infty}, \\
\text { slug/ft }\end{array}$ & $\begin{array}{c}T_{\infty}, \\
{ }^{\circ} R\end{array}$ \\
\hline A & 18.1 & $40^{\circ}$ & 18429 & $3.17 \times 10^{-7}$ & 433 \\
B & 24.3 & $40^{\circ}$ & 22705 & $1.12 \times 10^{-7}$ & 364
\end{tabular}

Table 2. Wind tunnel conditions for damage scenario computations

\begin{tabular}{cccccc} 
Tunnel & Gas Model & $M_{\infty}$ & $\begin{array}{c}U_{\infty}, \\
f t / s\end{array}$ & $\begin{array}{c}\rho_{\infty}, \\
\text { slug } / f t^{3}\end{array}$ & $\begin{array}{c}T_{\infty}, \\
{ }^{\circ} R\end{array}$ \\
\hline Mach 6 & Air, $\gamma=1.4$ & 6.00 & - & - & - \\
$\mathrm{CF}_{4}$ & $\mathrm{CF}_{4}$ & 5.85 & 2994 & $2.94 \times 10^{-5}$ & 387
\end{tabular}

computational analysis. Figure 3 shows Columbia's Mach number and angle of attack plotted against both time past entry interface and time (minutes and seconds only). The angle of attack oscillations are typical until near EI+600 sec (54:00). The beginning of off-nominal angle of attack profile 
begins near the time of the reversal in delta rolling moment trend (Fig. 1). The Mach number steadily decreases over the trajectory. Loss of signal occurred at 8:59:30 EST (EI+921) at approximately Mach 18 near an altitude of 200,000 ft. Table 3 summarizes the flow conditions for which FeLISA solutions were obtained and gives the corresponding timeline events.

Time Past Entry Interface (EI), sec

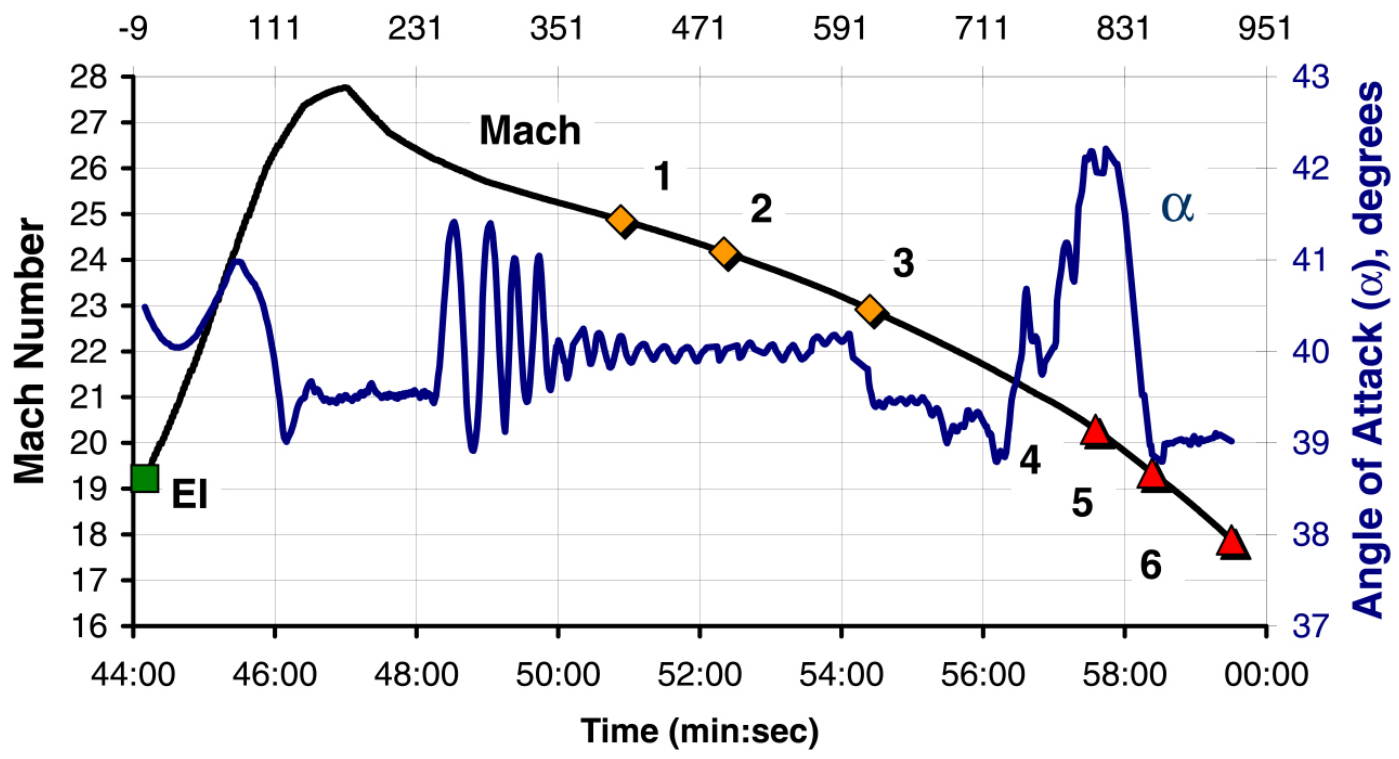

Figure 3. STS-107 entry Mach and angle of attack trajectory profile with CFD conditions

Table 3. STS-107 trajectory point conditions for damage scenario computations

\begin{tabular}{|c|c|c|c|c|c|c|c|c|}
\hline $\begin{array}{c}\text { CFD } \\
\text { Condition }\end{array}$ & Timeline Event & $\begin{array}{l}\text { Entry } \\
\text { Time }\end{array}$ & $\begin{array}{l}\text { Time Past } \\
\text { EI, s }\end{array}$ & $M_{\infty}$ & $\alpha$ & $\begin{array}{l}U_{\infty} \\
\mathrm{ft} / \mathrm{s}\end{array}$ & $\begin{array}{c}\rho_{\infty} \\
\operatorname{slug} / f t^{3}\end{array}$ & $\begin{array}{l}T_{\infty}, \\
{ }^{\circ} R\end{array}$ \\
\hline 1 & Start of peak heating & $50: 53.0$ & 404.0 & 24.9 & $40.2^{\circ}$ & 24116 & $7.57 \times 10^{-8}$ & 391 \\
\hline 2 & First off-nominal event & $52: 20.4$ & 491.4 & 24.2 & $40.0^{\circ}$ & 23554 & $1.02 \times 10^{-7}$ & 395 \\
\hline 3 & $\begin{array}{l}\text { Start of off-nominal } \\
\text { trend for mid-fuselage } \\
\text { bondline temps @ } \\
\text { x-stations } 1215 \text { and } \\
\text { 1410, }\end{array}$ & $54: 24.2$ & 615.2 & 22.9 & $39.6^{\circ}$ & 22505 & $1.55 \times 10^{-7}$ & 401 \\
\hline 4 & $\begin{array}{l}\text { Start of elevon roll trim } \\
\text { corrections }\end{array}$ & $57: 35.2$ & 806.2 & 20.3 & $42.0^{\circ}$ & 20210 & $2.61 \times 10^{-7}$ & 413 \\
\hline 5 & $\begin{array}{l}\text { Near start of sharp } \\
\text { aileron trim }\end{array}$ & $58: 23.2$ & 854.2 & 19.4 & $38.9^{\circ}$ & 19428 & $3.52 \times 10^{-7}$ & 420 \\
\hline 6 & Last good GPS point & $59: 30.4$ & 921.4 & 17.9 & $39.0^{\circ}$ & 18164 & $5.06 \times 10^{-7}$ & 429 \\
\hline
\end{tabular}

\section{Results}

\section{A. Initial Felisa Computations}

In the days immediately following the accident, numerous damage scenarios were proposed that focused on the impact on the left wing by a piece of foam from the external tank. Analysis performed during the mission 
had localized the foam impact to the region of RCC panels 5-9, and indicated that the point of impact had been downstream of the RCC wing leading edge. Wind tunnel testing was initiated, focusing on damage to the vehicle windside that could cause asymmetric boundary layer transition. Computations with the LAURA code and other viscous CFD codes were proposed to address the possibility of the foam damaging the wing leading edge in the vicinity of RCC panel 6 , but it was quickly realized that the complexity of modeling the damage with a structured grid would take several weeks. It was then proposed to use the FELISA code to obtain a rapid initial assessment of the flowfield created by a missing RCC panel.

The first FELISA computations on a geometry with a notch cut in RCC panel 6 were completed within 8 days after the accident. The geometry was an approximation developed by matching the RCC panel location from a figure in a 1995 report ${ }^{21}$ with the GridTool model. The notch was modeled with solid side surfaces; the open channel behind the RCC panels was not represented. Figure 4 shows the notch definition in relationship to the actual RCC panel 6 geometry that was utilized later in the investigation. The mesh for the baseline configuration was from an earlier study, 15 and the mesh for the damage configuration was developed by hand using GridTool and the same spacing definitions as the baseline mesh. These initial meshes had approximately $180 \mathrm{~K}$ surface triangles, $1.8 \mathrm{M}$ volume nodes, and $11 \mathrm{M}$ tetrahedra. The flow solver utilized the equilibrium air model at the STS-2 trajectory points, as given previously in Table 1. It should be noted that the original mesh was designed for computations at Mach 10-15; thus it was not optimized for the higher Mach number flows, where the shock is much closer to the body.

The surface $C_{p}$ distributions on the windside of the vehicle for the baseline and damaged configurations at STS-2 Condition B are shown in Figure 5 . The windward side showed only localized influence of the presence of the notch. The corresponding surface $C_{p}$ distributions on the fuselage side for the baseline and damaged configurations are shown in Fig. 66, with a compressed scale for $C_{p}$. The wing leeside and fuselage side show a strong footprint of a jet-like structure in the flow coming from the notch, then turning toward and impinging on the fuselage side. This impingement would increase the heating rate on the fuselage side, a trend that was identified by the OI flight data early in the investigation.

Streamlines for the baseline and missing RCC panel 6 at STS-2 Condition B are shown in Fig. 7 , superimposed on the right side of the vehicle. Baseline streamlines are blue; streamlines for the damaged configuration are red. The streamlines on the windward side (Figure 7(a) of the vehicle show that the flow pattern

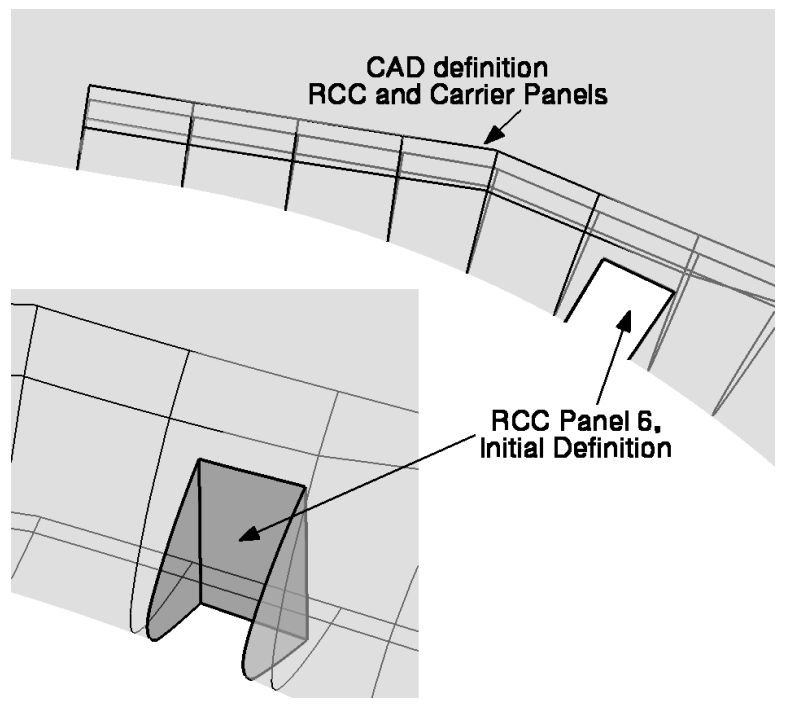

Figure 4. RCC panel 6, initial definition (notch)

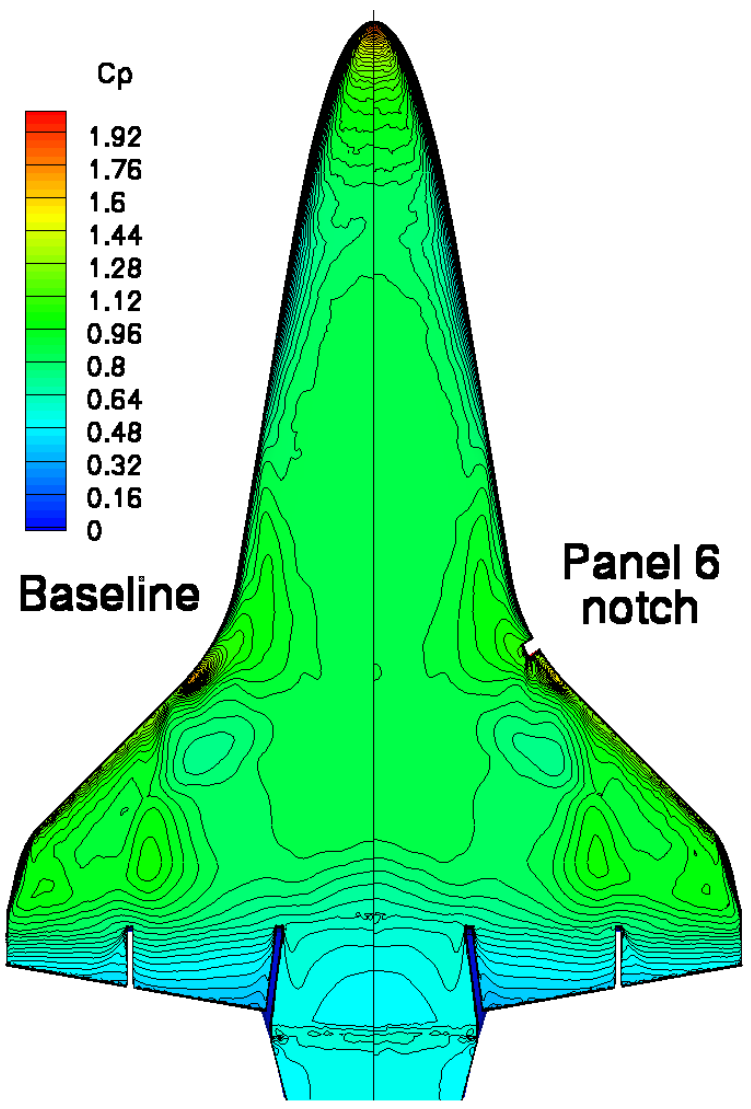

Figure 5. Surface pressure $\left(C_{p}\right)$ distribution, baseline and missing RCC panel 6, STS-2 condition B, windside is not affected inboard of the missing panel. The higher energy flow from the windward side is clearly channeled through the notch to the leeside, forming a jet-like 


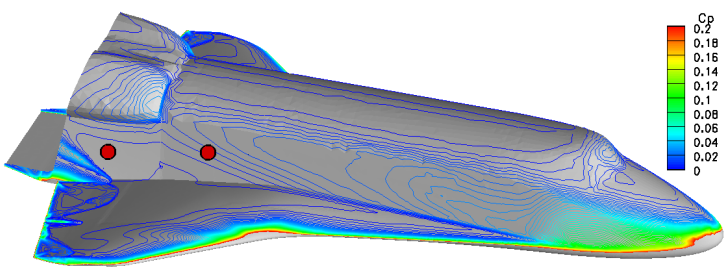

(a) Baseline

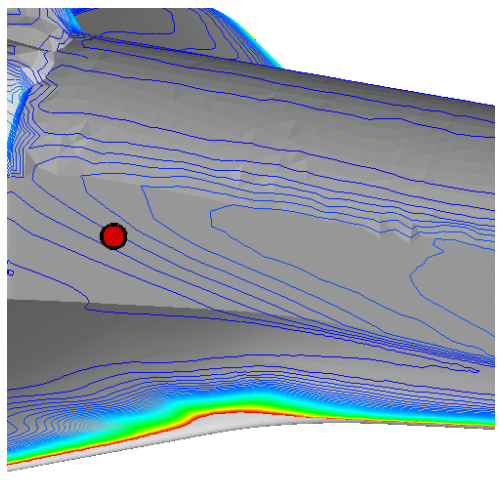

(c) Baseline, close

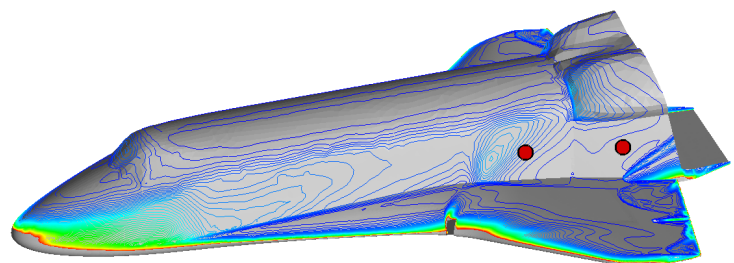

(b) Missing panel 6

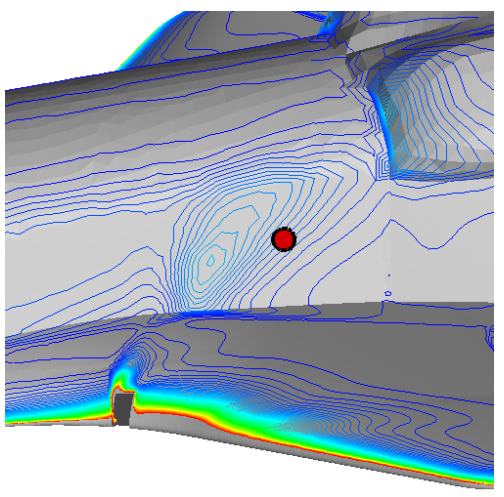

(d) Missing panel 6, close

Figure 6. Surface pressure $\left(C_{p}\right)$ distribution, baseline and missing RCC panel 6, STS-2 condition B, with location of side fuselage bondline sensors marked

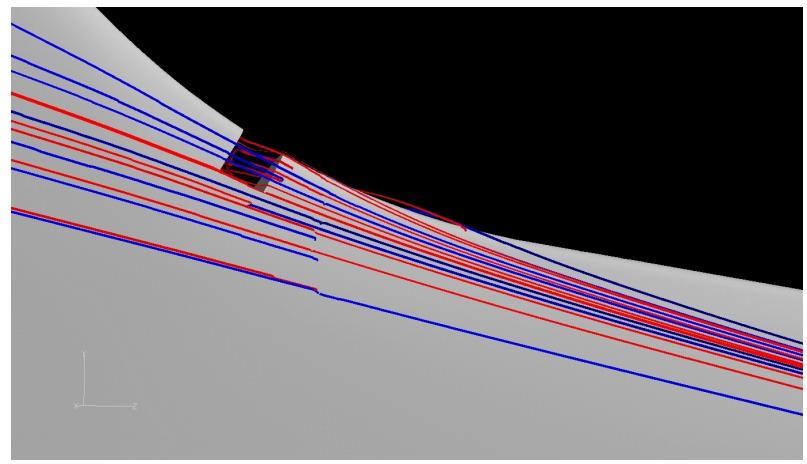

(a) Windward

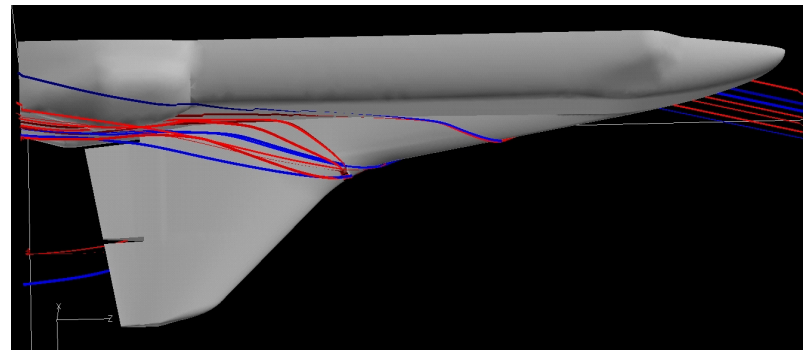

(c) Top

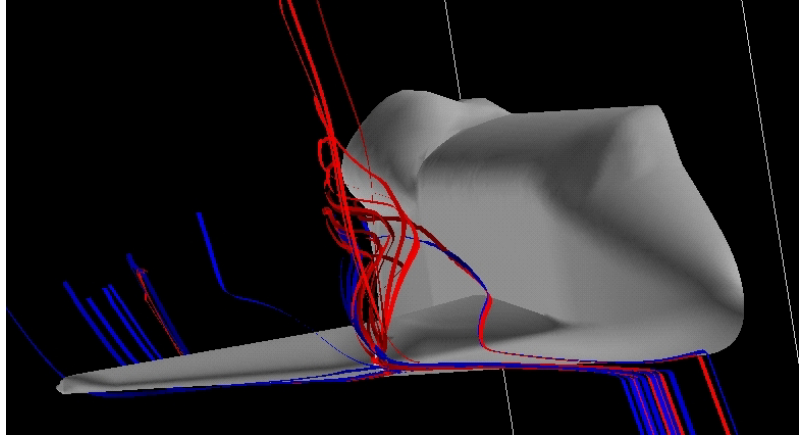

(b) Front

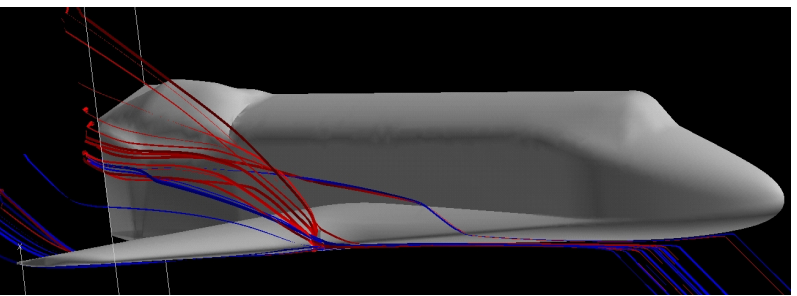

(d) Side

Figure 7. Streamlines, baseline (blue) and missing RCC panel 6 (red), STS-2 condition B 
flow structure. This jet-like flow carries substantially higher energy than the surrounding leeside flow, and therefore is not significantly influenced by the baseline flow. Figure $7(\mathrm{c})$ shows the flow through the notch turning almost perpendicular to the fuselage before impinging on it. The jet then turns downstream toward the OMS pod. The baseline streamlines from the flow coming over the wing leading edge do not reach the OMS pods.

This set of preliminary computations provided the first evidence to suggest that damage to the RCC WLE could cause the fuselage side temperature rise. These results were quickly followed by global heating measurements in Langley's 20-Inch Mach 6 air tunnel that showed a temperature rise on the left side fuselage that had a similar pattern to the pressure signature from the computations. 7

\section{B. Missing Full RCC Panel(s)}

After the initial FELISA computations and the wind tunnel heating tests on configurations with damage to the WLE showed promising results, systematic studies, both computational and experimental, were undertaken to characterize the effects of location (which RCC panel) and size (how many RCC panels) of WLE damage on the aerodynamics and aeroheating characteristics of the vehicle. At the beginning of this phase of the investigation, FELISA computations on configurations with single and multiple full RCC panels missing were proposed to serve two purposes. First, rapid aerodynamic results were required to provide initial estimates

Table 4. Full RCC panel(s) missing configurations and cases

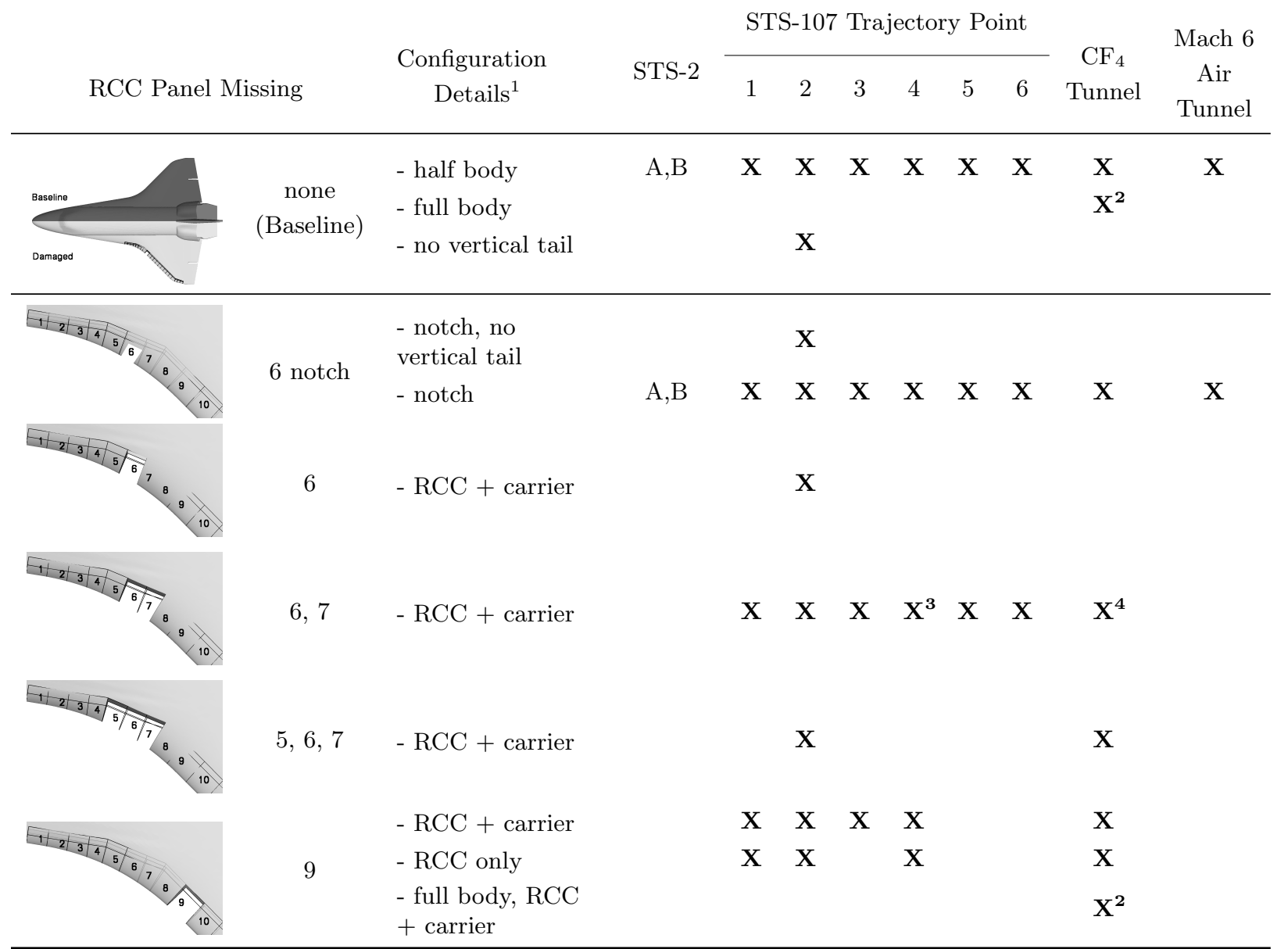

\footnotetext{
${ }^{1}$ half-body with vertical tail and bodyflap included unless otherwise noted

${ }^{2} \beta=-1^{\circ}, 0^{\circ}$, and $+1^{\circ}$

${ }^{3} \alpha=38^{\circ}, 40^{\circ}$, and $42^{\circ}$

${ }^{4} \alpha=40^{\circ}$
} 
of the delta aerodynamics in order to guide selection of the configurations to be tested in the $\mathrm{CF}_{4}$ tunnel. More importantly, it was crucial for the investigation to establish a link between the ground-based testing in the $\mathrm{CF}_{4}$ tunnel to the hypervelocity flight environment.

Inviscid flow solutions over a subset of the configurations being tested in the wind tunnels were computed with FELISA, for conditions at several STS-107 trajectory points and at $\mathrm{CF}_{4}$ tunnel conditions. The flow conditions used throughout the remainder of this study are given in Tables 2 and 3 . The baseline meshes were refined based on the initial solutions to better capture the bow shock and flow features for the hypervelocity flight conditions and tunnel conditions. Table 4 shows a planform thumbnail sketch and the flow conditions used for computation for each configuration. Most configurations were analyzed at more than one flight condition, and all at the $\mathrm{CF}_{4}$ tunnel condition. Only the initial panel 6 notch geometry was computed at the Mach 6 air tunnel condition. Meshes for the $\mathrm{CF}_{4}$ computations were on the order of $3.0 \mathrm{M}$ nodes. The meshes for the flight computations were larger (on the order of $4.8 \mathrm{M}$ nodes) in order to resolve the bow shock that was closer to the body.

Several criteria are used in assessing convergence of a FELISA solution. The methodology in FELISA preserves total enthalpy so that a converged solution has a constant enthalpy throughout the flowfield; the maximum and minimum total enthalpies are tracked for each iteration of a solu-

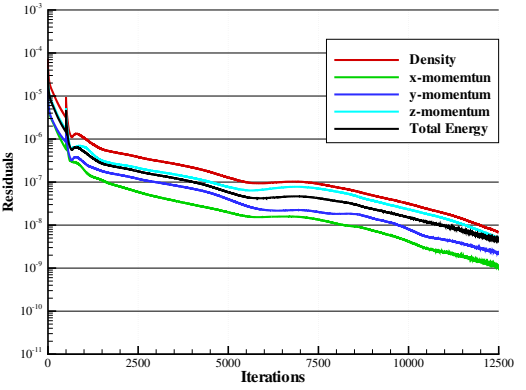

(a) Residual history

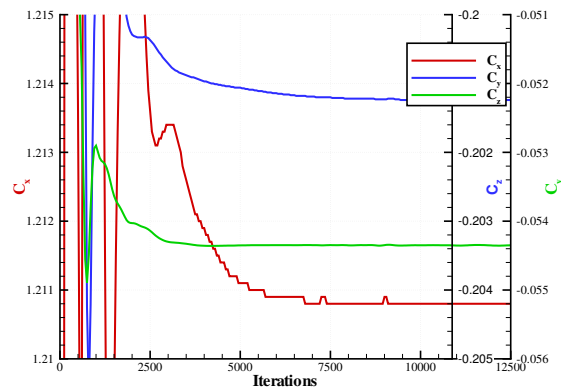

(c) Force history

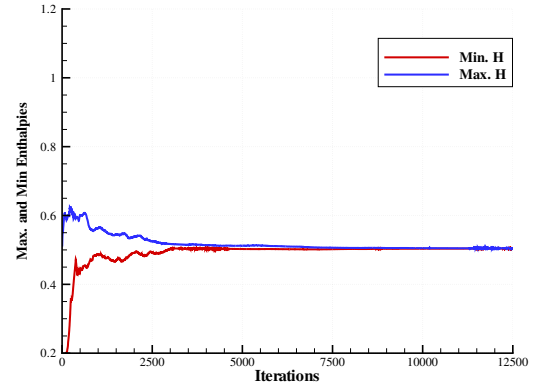

(b) Enthalpy history

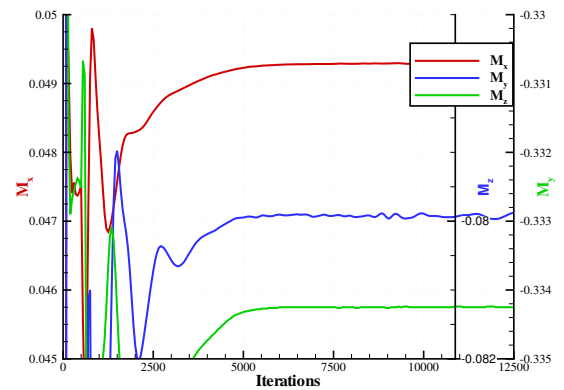

(d) Moment history

Figure 8. Typical history plots to monitor convergence of FELISA computation

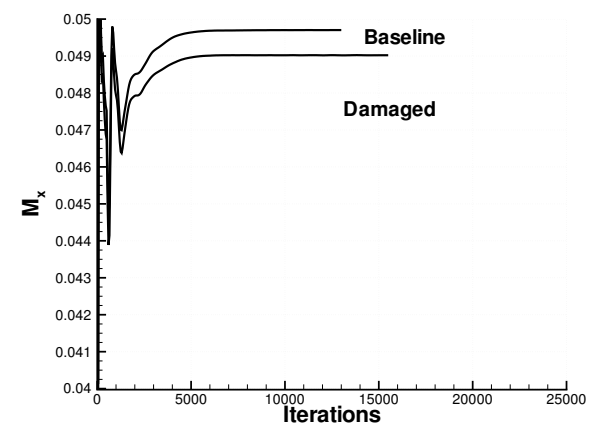

(a) Steady damage solution

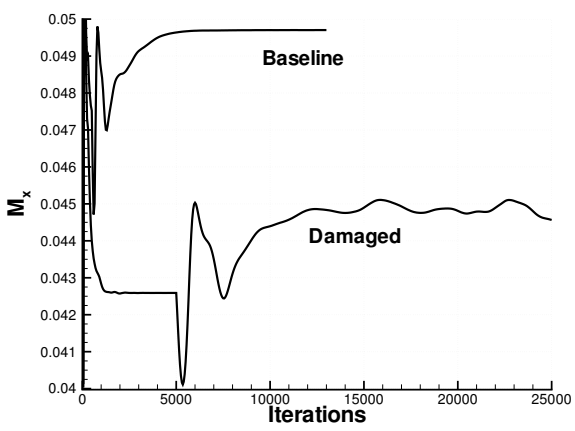

(b) Oscillatory damage solution

Figure 9. Typical moment history plots to monitor solution convergence of damage configuration relative to baseline configuration

namic loads are of primary interest, their convergence is also tracked. Figure 8 shows the typical set of plots that are evaluated to assess convergence. Even though the residual is still dropping, the aerodynamic 
loads and the enthalpies have converged to steady values. For many of the damage scenarios evaluated, the solutions did not converge to steady state. This is not unexpected given the complexity of the WLE damage configurations being evaluated. In these oscillatory cases, the convergence history of the loads for the baseline and the damaged configuration were co-plotted, to determine if the oscillation of the aerodynamic loads was larger than the delta aerodynamics. Figure $9(\mathrm{a})$ shows the history of the moment about the $\mathrm{x}$-axis (related to the yawing moment) for a damaged (windward surface depression) and a baseline solution, where the damaged solution has reached a steady state. Figure 9(b) shows a similar plot for a damaged configuration (half panel 9 with upper carrier panel removed) with definite oscillations in the loads. The magnitude of the oscillations, however, are small compared to the difference between the damaged and the baseline. The practical implication of the unsteady nature of many of the computations is that there is a bound on the delta aerodynamics, although the data was not reported in this manner because the trend in the delta aerodynamics over a progression of damage is more important than an exact numerical value for the delta aerodynamics.

\section{Baseline Configuration}

Aerodynamics computed with FeLISA and predicted by the Orbiter OADB for the baseline Orbiter configuration at the STS-107 flight conditions (Table 3p are shown in Fig. 10. For pitching moment, the FelisA data is in better agreement with the Orbiter OADB data later in the flight, suggesting that the inviscid equilibrium chemistry model is not as appropriate for the higher Mach number range $\left(M_{\infty}>21\right)$. Additionally, the FELISA pitching moment results are well within the uncertainty $( \pm 0.005)$ of the $\mathrm{OADB}^{2}$ data. , except for the highest Mach number cases (CFD conditions 1 and 2). The normal force comparison is good and the axial force comparison is poor, as is typical for inviscid computations.

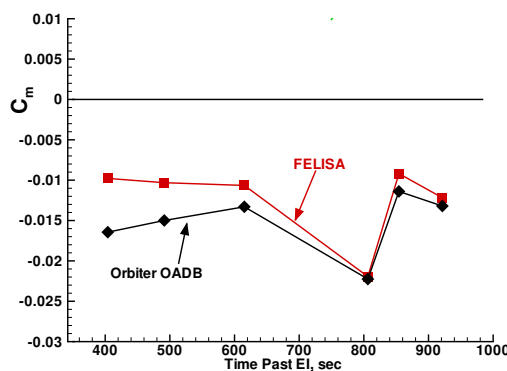

(a) Pitching moment coefficient

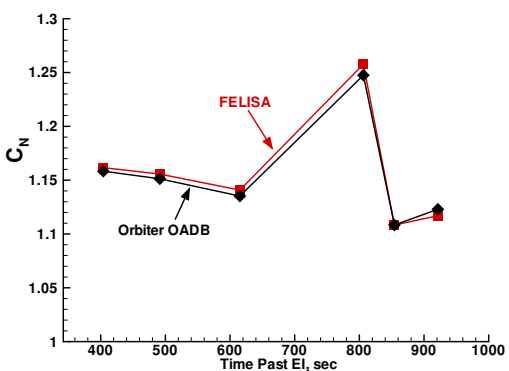

(b) Normal force coefficient

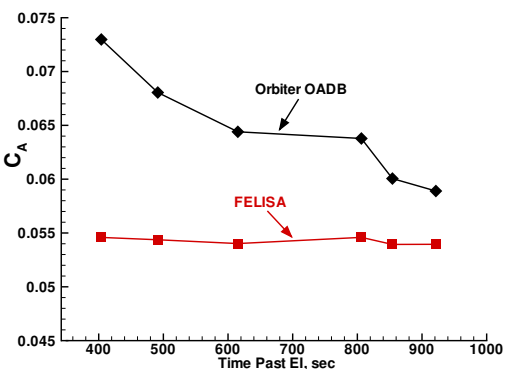

(c) Axial force coefficient

Figure 10. Aerodynamics at STS-107 trajectory points for FELISA computation and Orbiter OADB

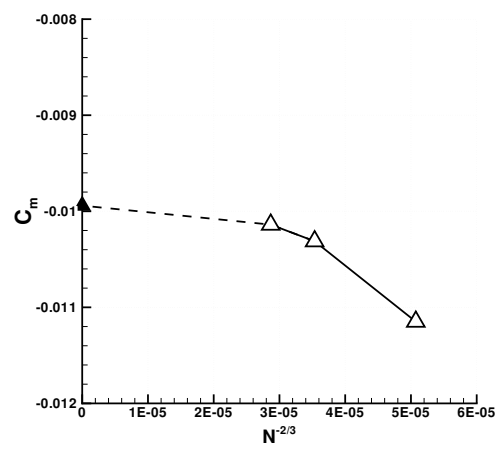

(a) Pitching moment coefficient

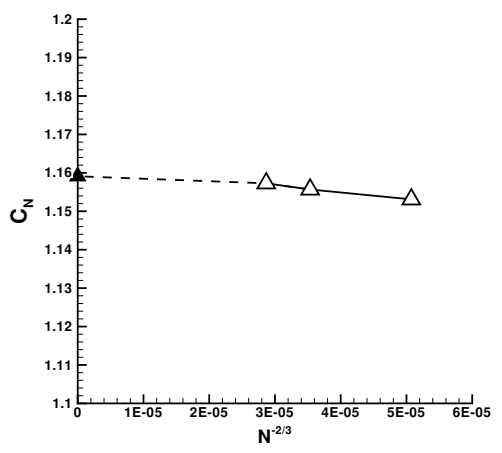

(b) Normal force coefficient

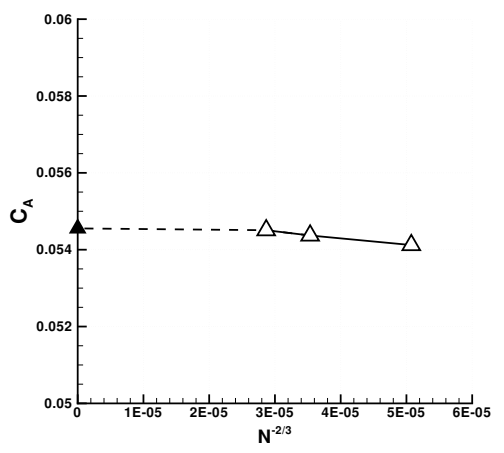

(c) Axial force coefficient

Figure 11. Baseline Orbiter aerodynamics for several meshes at $M_{\infty}=24.2$ (CFD condition 2) versus number of nodes to the $-2 / 3$ power, with the Richardson extrapolations to an infinite mesh 
The forces and moments from several meshes of increasing size on the baseline configuration were computed in order to assess the level of grid convergence of the medium mesh (soi), which was used for the flight computations. The coarse (soj) and the fine $(s o k)$ meshes were generated by scaling the mesh spacings of the medium (soi) mesh, preserving the relative spacing distribution of the mesh. The mesh sizes are summarized in Table 5 .

Figure 11 shows the pitching moment, normal force, and axial force coefficients for the baseline configuration at CFD condition 2 plotted against

Table 5. Meshes for baseline orbiter grid convergence

\begin{tabular}{cccc}
\multirow{2}{*}{$\begin{array}{c}\text { Mesh } \\
\text { Name }\end{array}$} & Surface & \multicolumn{2}{c}{ Volume } \\
\cline { 3 - 4 } Triangles & Nodes & Tetrahedra \\
\hline \multirow{2}{*}{ soj } & $330 \mathrm{~K}$ & $2.8 \mathrm{M}$ & $16 \mathrm{M}$ \\
so $i$ & $480 \mathrm{~K}$ & $4.8 \mathrm{M}$ & $28 \mathrm{M}$ \\
sok & $590 \mathrm{~K}$ & $6.5 \mathrm{M}$ & $39 \mathrm{M}$
\end{tabular}

$N^{-2 / 3}$ (a measure of mesh spacing, $h$, for an unstructured mesh), where $N$ is the number of nodes in the mesh. The dashed lines in Fig. 11] show a Richardson extrapolation for each coefficient based on the medium and fine mesh solutions which were computed assuming a second order convergence rate. The normal and axial forces are well converged; the differences between the medium mesh solution and the infinite mesh extrapolation are $0.5 \%$ and $0.3 \%$, respectively. The pitching moment is less grid converged, with a difference of 0.00037 , or $3.7 \%$. This is on the order of $\Delta C_{m}$ for the missing RCC panel 6 and panel 9 cases.

With computational simulations, the contributions to the vehicle aerodynamics of each vehicle component (vertical tail, wing, etc.) can be isolated. The delineation of the vehicle components that are used throughout this work is shown in Fig. 12. The pitching moment coefficient (at CFD condition 2) for several vehicle components are plotted against $N^{-2 / 3}$ in Fig 13 in order to assess the grid convergence in different regions of the mesh. The OMS pod and vertical tail components are not included in the grid convergence analysis, as their contributions to $C_{m}$ are essentially zero. The $C_{m}$ scale is adjusted so that the spacing is the same $\left(C_{m}\right.$ axis is .004 long) for all plots. The fuselage and wing are well converged, with differences between the medium mesh solution and the infinite mesh extrapolation of \pm 0.00005 . The forebody, windside, and bodyflap are less converged, with differences of $0.0005,0.0002$, and -0.0003 , respectively. This indi-

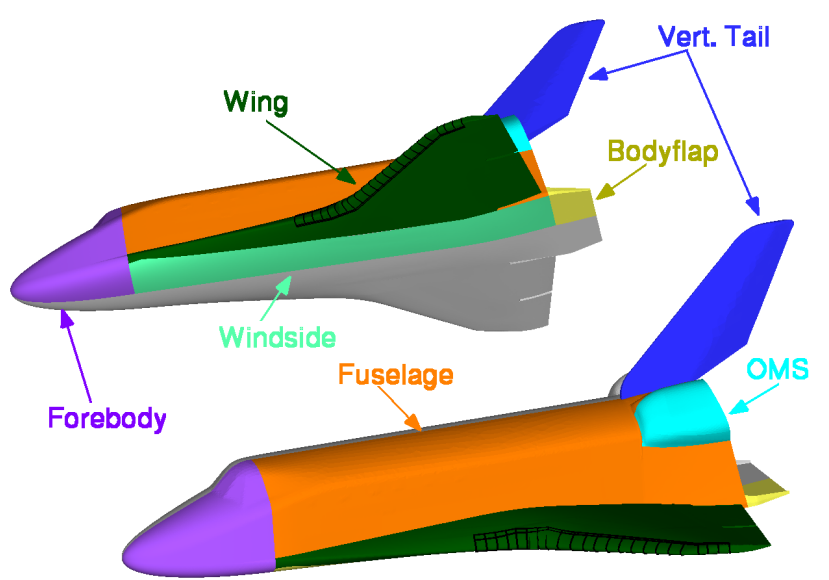

Figure 12. Component definition for FELISA Orbiter model cates that for CFD condition $2\left(M_{\infty}=24.2\right)$, the finest meshes still do not fully resolve the flow features on the windside. Since the primary regions of interest for all of the damage scenarios are the wing and side fuselage, the grid convergence plots show that the baseline medium mesh is reasonably grid converged for these primary regions of interest, thereby providing some measure of confidence in the damage scenario meshes.

\section{Damage Scenario Configurations}

The pitching moment and normal force coefficients for the baseline and missing RCC panels 6 and 7 configurations at a constant $\alpha=40^{\circ}$ are shown in Figure 14 for a range of flight Mach numbers. The results for the $\mathrm{CF}_{4}$ and Mach 6 perfect gas air conditions are included as straight lines to emphasize that they are not plotted as functions of Mach number. The differences between the flight, $\mathrm{CF}_{4}$, and Mach 6 air aerodynamics are large. This is to be expected as the flow conditions are significantly different. For a given flow condition, the difference between the baseline and the damage configuration aerodynamics (the delta aerodynamics) is small, except for $C_{A}$ (not shown). Also, it appears that the delta aerodynamics for the flight conditions are relatively constant, and of the same order of magnitude as for the $\mathrm{CF}_{4}$ conditions. This gives an initial indication that the delta aerodynamics are relatively insensitive to the flow condition.

Throughout this study, computations were made on half-body configurations, thus ignoring any asymmetry in the flow at the symmetry plane. In order to assess the impact of this practical modeling decision, 


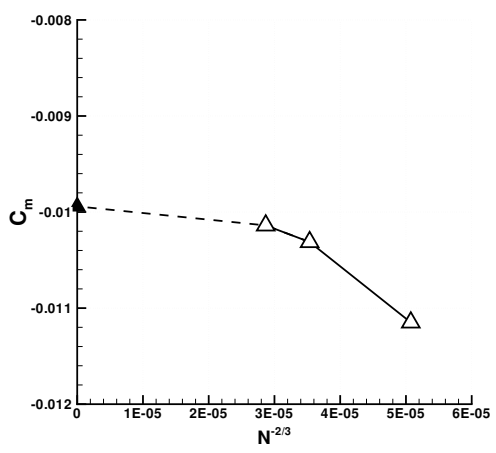

(a) Full Vehicle (repeated from Fig. $11(\mathrm{a})$

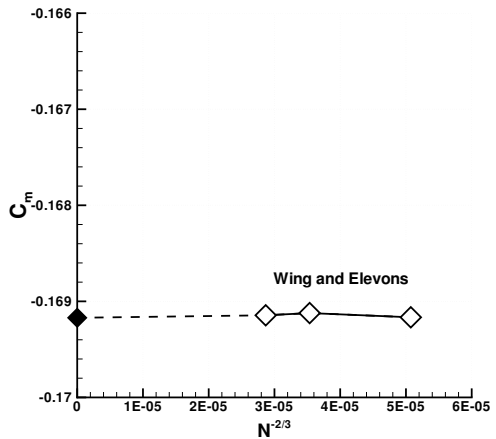

(d) Wing and Elevons

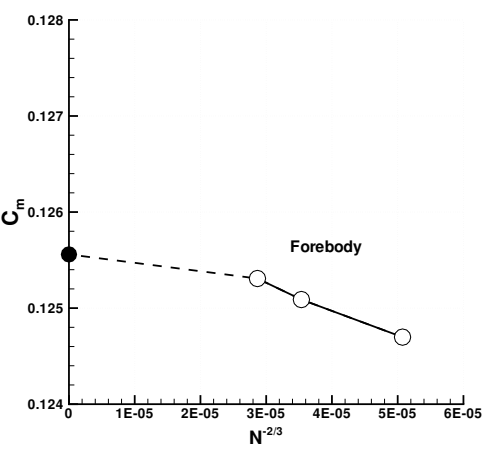

(b) Forebody

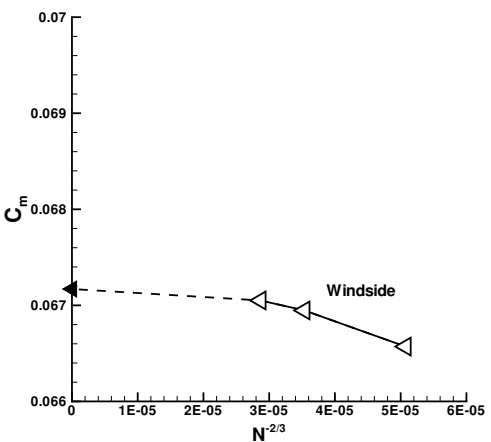

(e) Windside

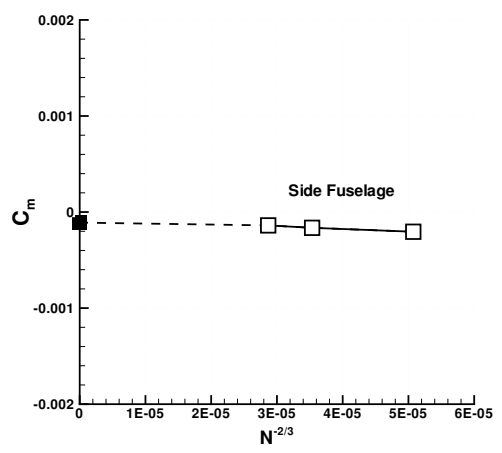

(c) Fuselage

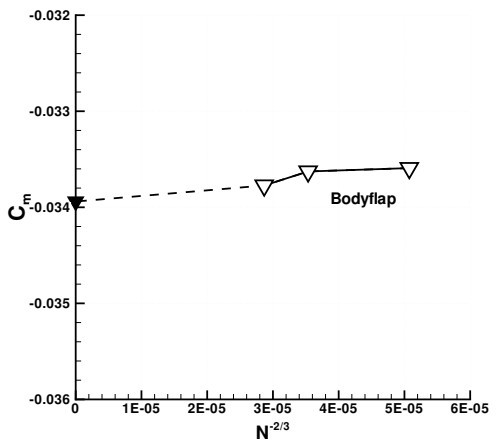

(f) Bodyflap

Figure 13. Pitching moment for baseline Orbiter and various vehicle components at $M_{\infty}=24.2$ (CFD condition 2) versus number of nodes to the $-2 / 3$ power, with the Richardson extrapolations to an infinite mesh

one set of $\mathrm{CF}_{4}$ computations was made with a full configuration having an undamaged right side, and a missing RCC panel 9 on the left. The delta force and moment coefficients from these computations are shown in Fig. 15 plotted versus sideslip angle $\beta$. Corresponding coefficients computed using a missing panel 9 half-body configuration (at $\beta=0$ ) are also shown, with filled symbols. The delta aerodynamics show little variation with $\beta$, for this range, and the half-body deltas are consistent with the full body deltas. These two observations demonstrate that

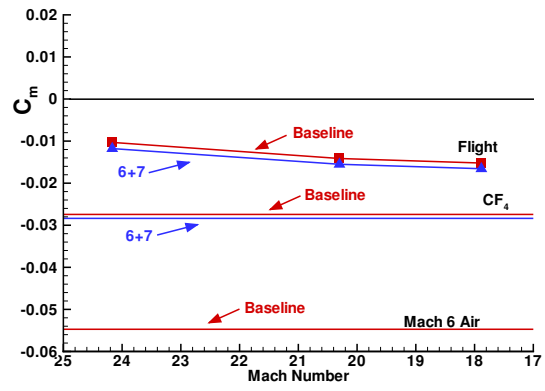

(a) Pitching moment coefficient

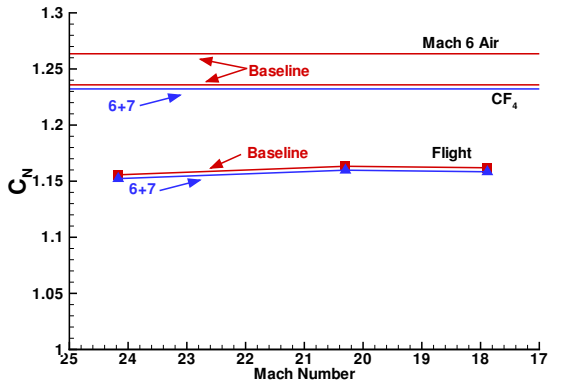

(b) Normal Force Coefficient

Figure 14. Aerodynamics of baseline and missing RCC panels 6 and 7 configurations at Flight, $\mathrm{CF}_{4}$, and Mach 6 tunnel conditions

due to flow across the vehicle symmetry plane, and supports the decision to utilize half-bodies for the damage scenario computations.

In order to understand how the $\mathrm{CF}_{4}$ flowfield compares to the flight environment, side fuselage $C_{p}$ contours, shown in Fig. 16, are examined for the baseline, missing panel 6, and missing panel 9 configurations 
at both flight (CFD Condition 2) and $\mathrm{CF}_{4}$ tunnel conditions. The two red dots on the side fuselage indicate the approximate location of the two bondline sensors that showed a higher than nominal temperature rise prior to loss of signal. The flight condition produces a higher overall pressure level than the $\mathrm{CF}_{4}$ conditions. The disturbance on the side fuselage is located further downstream for the $\mathrm{CF}_{4}$ cases than for flight. It is stronger and further downstream for the panel 9 cases as compared to panel 6 . While the disturbance is somewhat different in location and strength between flight and $\mathrm{CF}_{4}$,

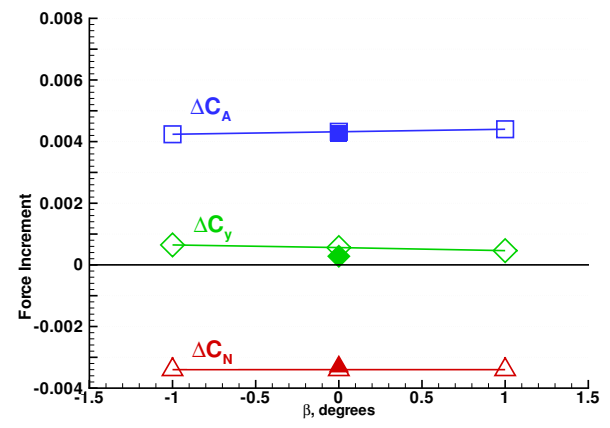

(a) Delta force coefficients

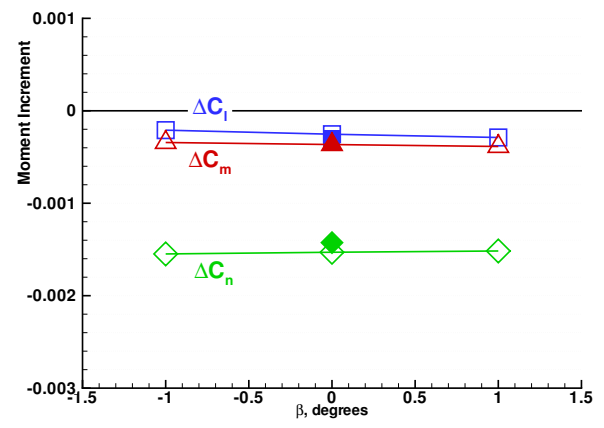

(b) Delta moment coefficients

Figure 15. Delta aerodynamic coefficients for full vehicle (open symbols) with missing RCC panel 9 for range of sideslip angles, $\beta$ and half-body (filled symbols) at $\beta=0$, for $\alpha=40^{\circ}, \mathbf{C F}_{4}$ conditions

the disturbance is similar. This suggests that tests in the $\mathrm{CF}_{4}$ tunnel provide a reasonably good simulation of the changes in surface pressure due to WLE damage scenarios at flight conditions.

The delta aerodynamic moments computed with FeLISA for several panel out configurations at flight (CFD condition 2) and $\mathrm{CF}_{4}$ are compared to $\mathrm{CF}_{4}$ tunnel data in Fig. 17. The x-axis of the plot is simply

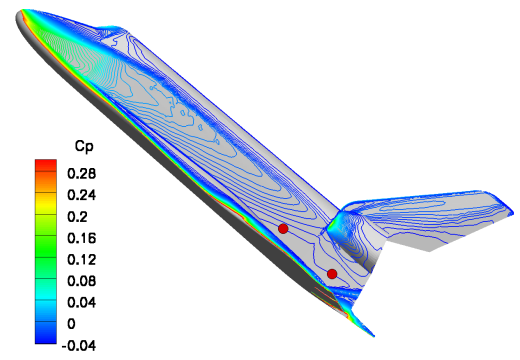

(a) $\mathrm{CF}_{4}$, Baseline

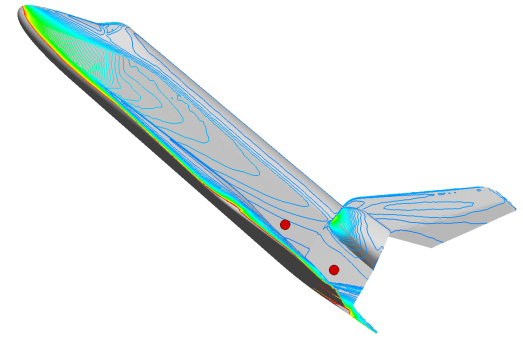

(d) Flight, Baseline

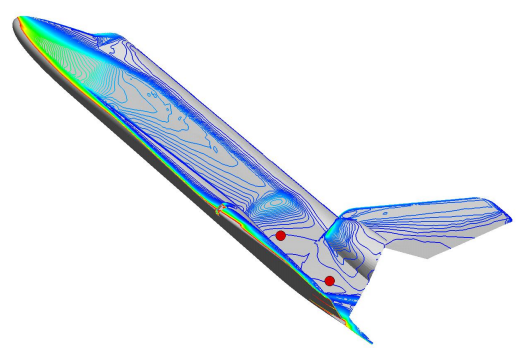

(b) $\mathrm{CF}_{4}$, Panel 6

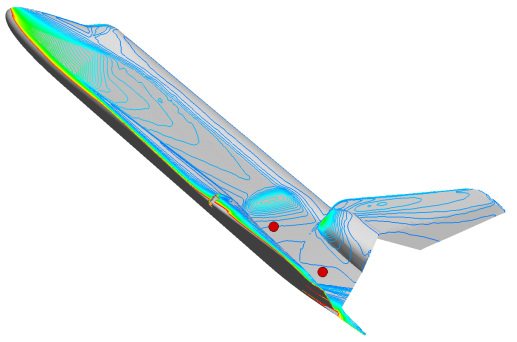

(e) Flight, Panel 6

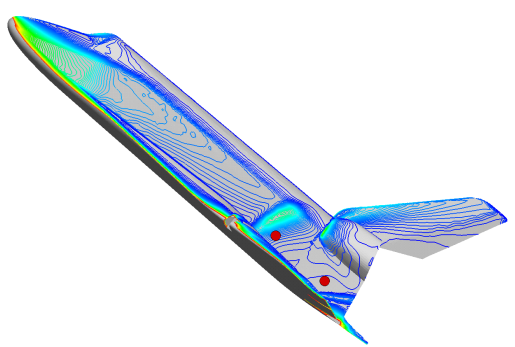

(c) $\mathrm{CF}_{4}$, Panel 9

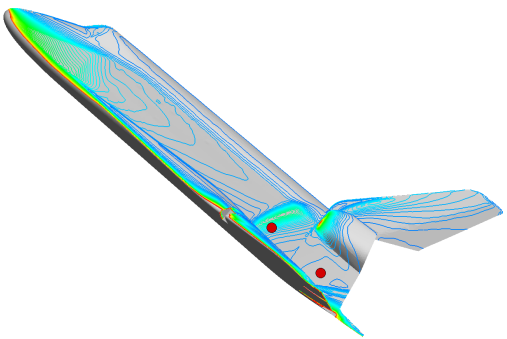

(f) Flight, Panel 9

Figure 16. Surface pressure $\left(C_{p}\right)$ distributions for baseline, missing RCC panel 6, and missing RCC panel 9 at flight (CFD condition 2) and $\mathrm{CF}_{4}$ conditions (location of side fuselage bondline sensors designated) 


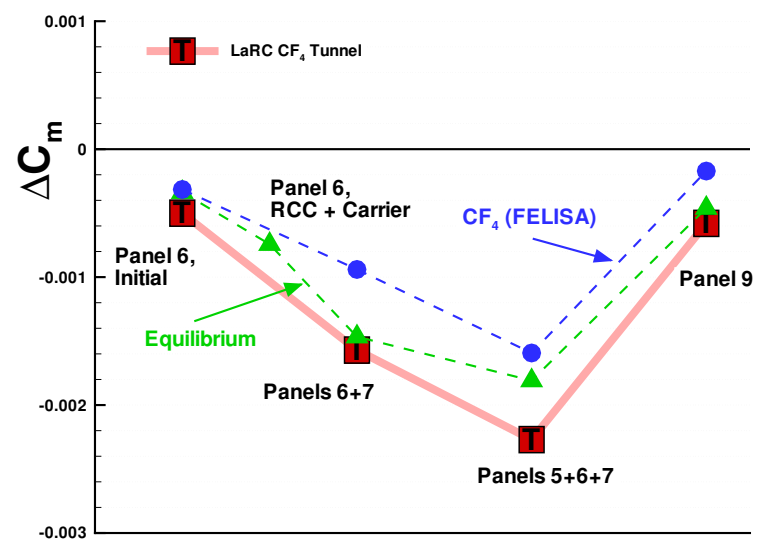

(a) Delta pitching moment

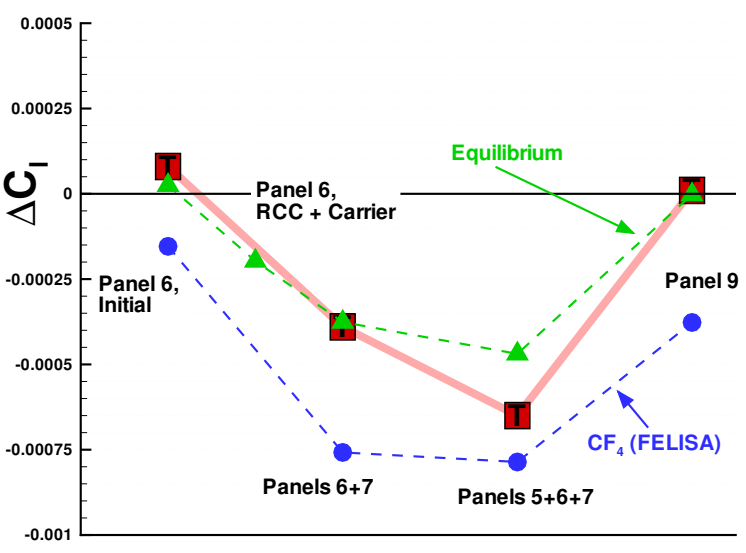

(b) Delta rolling moment

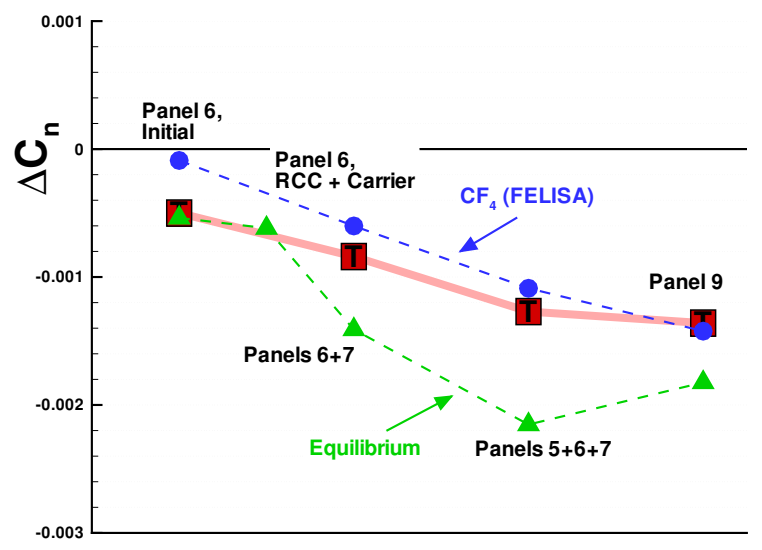

(c) Delta yawing moment

Figure 17. Delta aerodynamics for full RCC panel(s) missing configurations, FELISA equilibrium (CFD Condition 2), Felisa $\mathbf{C F}_{4}$, and $\mathbf{C F}_{4}$ tunnel data

the configuration (labeled individually). The lines connecting the points for each configuration are included only to illustrate the trends; there is no expectation that interim damages can be predicted. Magnitudes of the predicted aerodynamic moments varied with the geometry, and to a lesser degree with flow condition (Mach 6 air, $\mathrm{CF}_{4}$, and flight). As additional RCC panels are removed (panel 6, then $6+7$, then $5+6+7$ ), the moment increments become more negative. For the two single missing panel cases (panel 6 and 9), $\Delta C_{m}$ and $\Delta C_{l}$ remain relatively constant while $\Delta C_{n}$ decreases significantly from panel 6 to panel 9 . A single FELISA solution at flight (CFD condition 2) was computed for the full missing RCC panel $6(\mathrm{RCC}+$ carrier panel) to compare to the initial, or notched panel 6 results. There is a noticeable decrease in $\Delta C_{m}$ and $\Delta C_{l}$, and less effect on $\Delta C_{n}$. The results suggest that removing more material at the same location has a noticeable negative impact on $\Delta C_{m}$ and $\Delta C_{l}$, and less effect on $\Delta C_{n}$.

Overall, the qualitative agreement between the computations and the tunnel data is excellent, although there are differences in magnitude. Comparing the computed $\mathrm{CF}_{4}$ values (blue) to the measured data (red), FELISA predicts a larger negative $\Delta C_{l}$, smaller negative $\Delta C_{m}$, and closely agrees with $\Delta C_{n}$. When comparing flight (equilibrium air) to $\mathrm{CF}_{4}$ predictions, the flight computations produce consistently larger negative pitch and yaw increments, while predicting smaller negative rolling moment increments. While these differences appear large on the scales plotted in Fig. 17, the magnitude of all of the delta moments for the missing panel configurations represent very small aerodynamic values. The level of correlation between the flight and $\mathrm{CF}_{4}$ computations and the wind tunnel data shown in Fig. 17 strongly suggest that the trends shown in the wind tunnel results are valid for STS-107 flight conditions. 


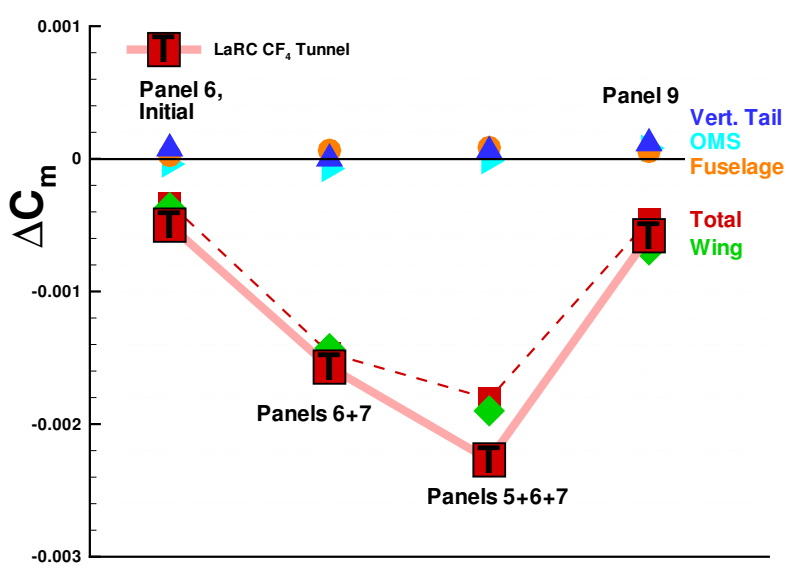

(a) Delta pitching moment, Flight

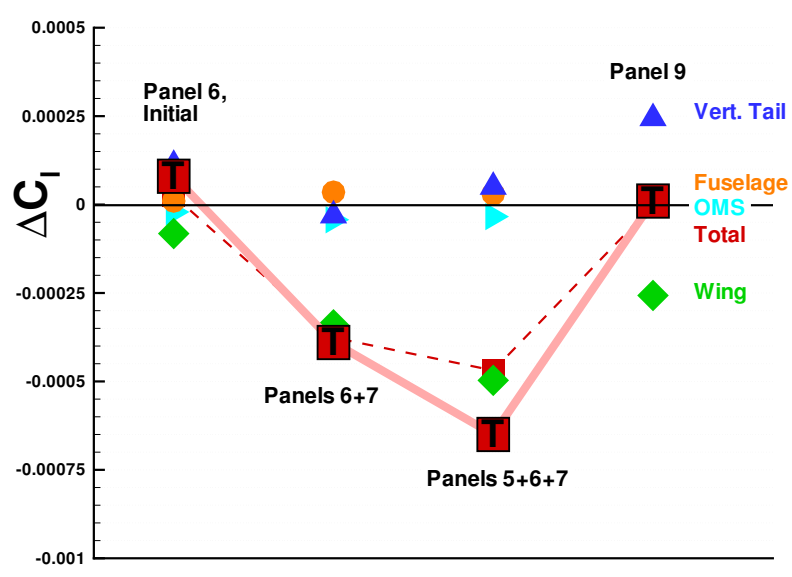

(c) Delta rolling moment, Flight

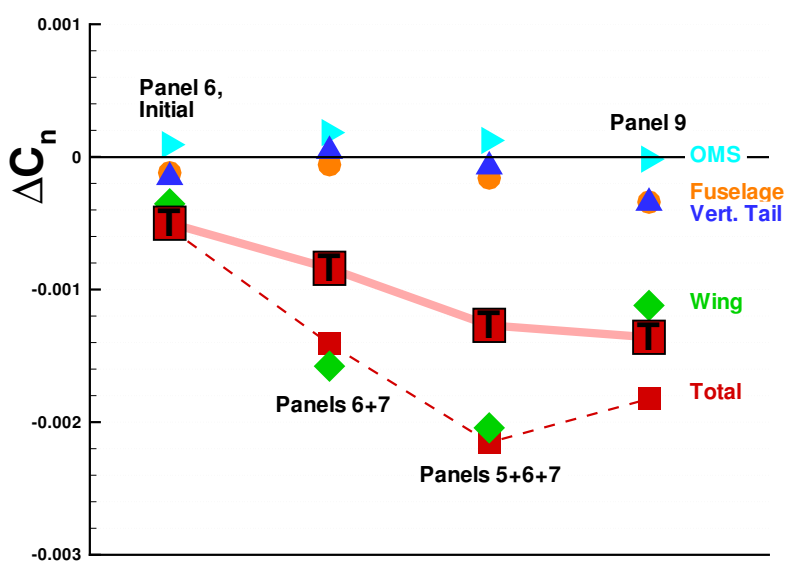

(e) Delta yawing moment, Flight

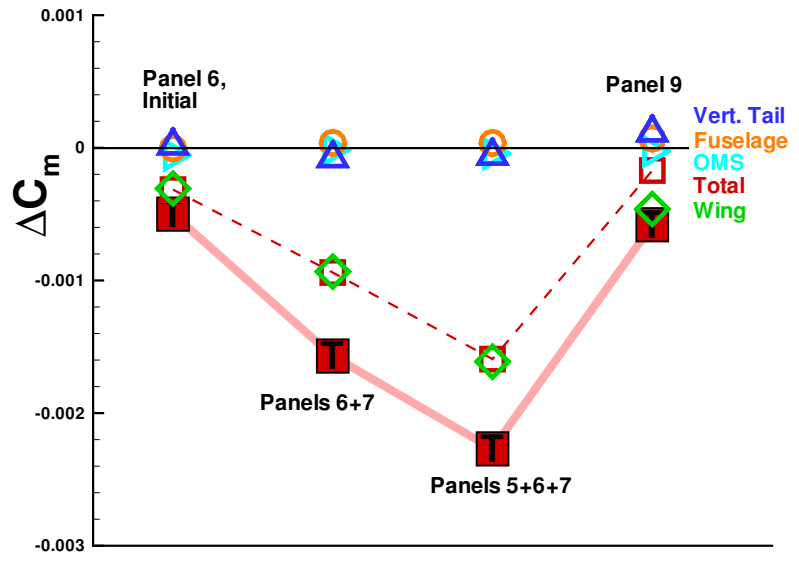

(b) Delta pitching moment, $\mathrm{CF}_{4}$

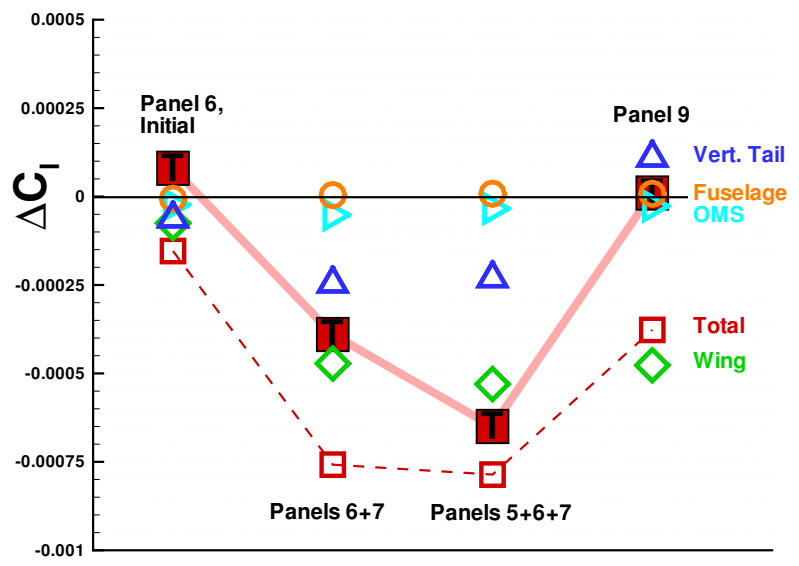

(d) Delta rolling moment, $\mathrm{CF}_{4}$

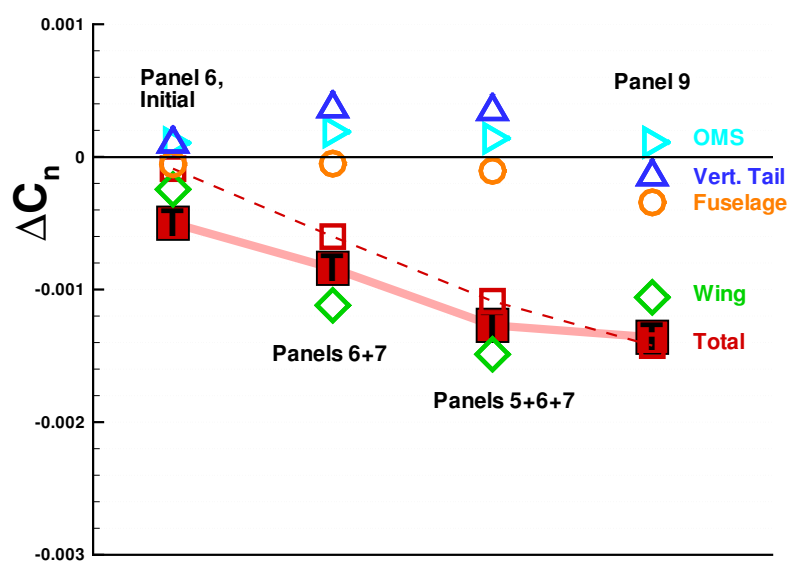

(f) Delta yawing moment, $\mathrm{CF}_{4}$

Figure 18. Component breakdown of delta aerodynamics for full RCC panel(s) missing configurations, FELISA equilibrium (CFD Condition 2), FELISA $\mathbf{C F}_{4}$, and $\mathbf{C F}_{4}$ tunnel 
The contributions of the vertical tail, wing, OMS pod, and fuselage regions of the Orbiter (as defined in Fig. 12 to the total delta aerodynamic moments for missing panel configurations at flight conditions (CFD condition 2, solid symbols) and $\mathrm{CF}_{4}$ tunnel conditions (hollow symbols) are shown in Figure 18. Also shown are the measured aerodynamic moments for the $\mathrm{CF}_{4}$ tunnel. As in Fig. 17, the missing panel configuration is plotted along the X-axis. Each component is color coded according to the colors in Fig. 12, and labeled on the plot, with the solid symbols representing flight computations.

Figures 18(a) and 18(b) clearly show that the $\Delta C_{m}$ due to the wing dominates the total delta pitching moment for both flight and $\mathrm{CF}_{4}$ conditions. For the multiple missing panel cases $(6+7,5+6+7)$ at flight conditions, Figs. 18(c) and 18(e) show that the delta rolling and yawing moments are also dominated by the wing. For the single missing panels, however, the influences of the vertical tail and wing balance each other in roll, essentially yielding a zero total increment. The vertical tail, the fuselage and the wing all produce negative increments for yawing moment, thereby providing a relatively large, negative delta yawing moment. The vertical tail contributions are more pronounced in flight for missing panel 9 than for missing panel 6. For $\mathrm{CF}_{4}$ conditions (Figs. 18(d) and 18(f)], the vertical tail gives a positive contribution to $\Delta C_{l}$ and a negative contribution to $\Delta C_{n}$ only for missing panel 9 , and these contributions are small. Overall the component breakdown results indicate that, for these configurations, there is not a large enough delta rolling moment contribution from the vertical tail to cause a substantial positive (right wing down) total delta rolling moment as seen late in flight.

Several of the missing panel configurations were run at multiple flight conditions to establish trends in the delta aerodynamics due to variations in the flight conditions. Figure 19 shows the computed delta

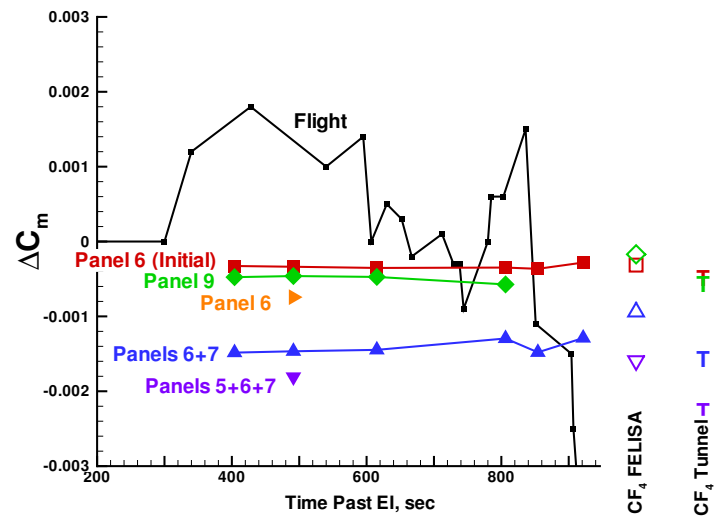

(a) Delta pitching moment

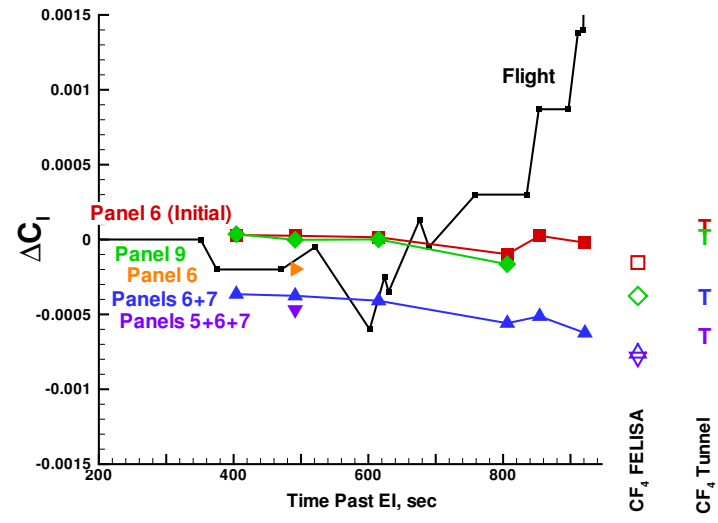

(b) Delta rolling moment

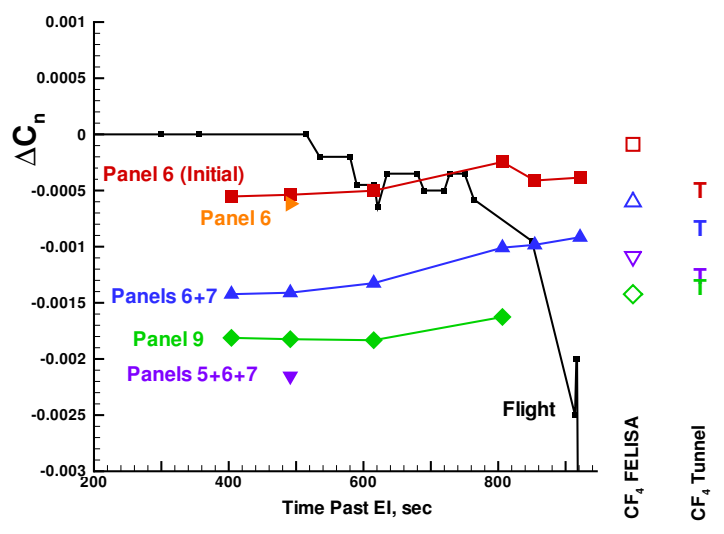

(c) Delta yawing moment

Figure 19. Delta aerodynamics for full RCC panel(s) missing configurations at multiple trajectory locations, FELISA $\mathbf{C F}_{4}$, and $\mathbf{C F}_{4}$ Tunnel 
aerodynamic moments and the extracted flight increments plotted against time from EI. The angle of attack varies between $39^{\circ}$ and $42^{\circ}$ (See Table 4 for $M_{\infty}$ and $\alpha$ at each point). The $\mathrm{CF}_{4}$ computational results and tunnel data are also shown for comparison. The delta pitching moment (Fig. 19(a) shows little variation with time over the trajectory for each of the missing panel configurations. The delta rolling moment (Fig. 19(b)] tends to increase negatively toward the end of the trajectory, but the variation is small. The delta yawing moment (Fig. 19(c) shows a definite more positive (smaller value) trend across the trajectory. The $\mathrm{CF}_{4}$ computational results and tunnel data appear to follow the $\Delta C_{l}$ and $\Delta C_{n}$ trends in time as if the $\mathrm{CF}_{4}$ condition simulates a flight Mach number somewhat lower than the $M_{\infty}=17.9$ point (CFD condition 6) However, because both Mach number and angle of attack are varying through the trajectory, it is not possible from this plot to isolate the source of the variations.

Several additional computations on the missing panels $6+7$ configuration were made to isolate the Mach number and the angle of attack effects in the delta aerodynamics. Figure 20 shows that, at a constant Mach number of 20.2 (CFD condition 4), there is little variation in the delta aerodynamics with angle of attack. Figure 21 shows the delta aerodynamics plotted against decreasing Mach number (to be consistent with increasing time past EI) at a constant angle of attack of $40^{\circ}$. As Mach number decreases, the delta rolling moment shows a shallow trend toward larger negative values. The delta yawing moment shows a stronger variation with Mach number, trending toward a smaller negative value. Referring back to Fig. 17, the differences in $\Delta C_{l}$ and $\Delta C_{n}$ between the flight and $\mathrm{CF}_{4}$ conditions are consistent with the $\mathrm{CF}_{4}$ condition representing a Mach number somewhat lower than the Mach 24.2 flight condition shown in that figure.

Overall, the computational results (both for flight and

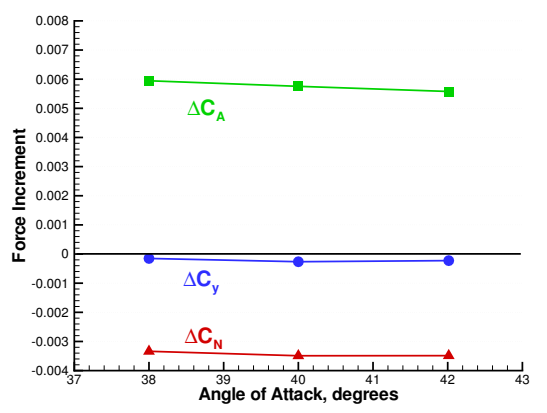

(a) Delta force coefficients

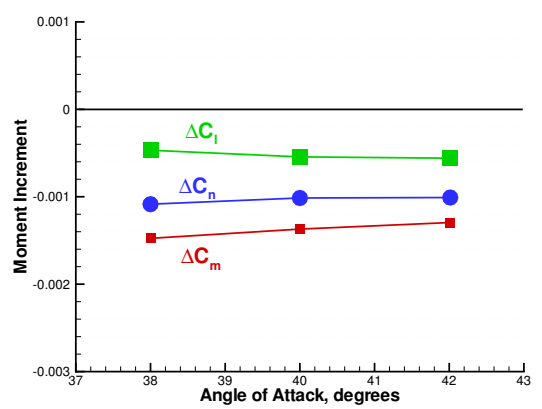

(b) Delta moment coefficients

Figure 20. Delta aerodynamic coefficients for missing RCC panels $6+7$ for range of angles of attack, $\alpha$, at $M_{\infty}=20.2$ (CFD condition 4)

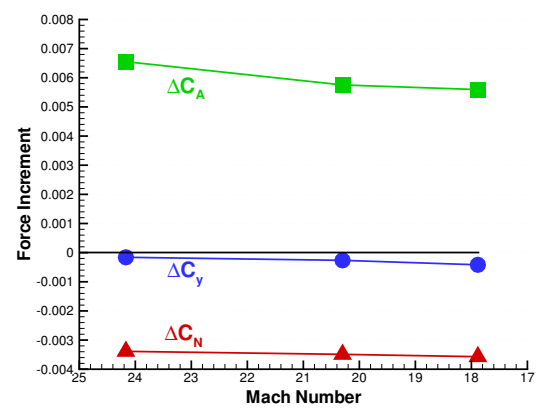

(a) Delta force coefficients

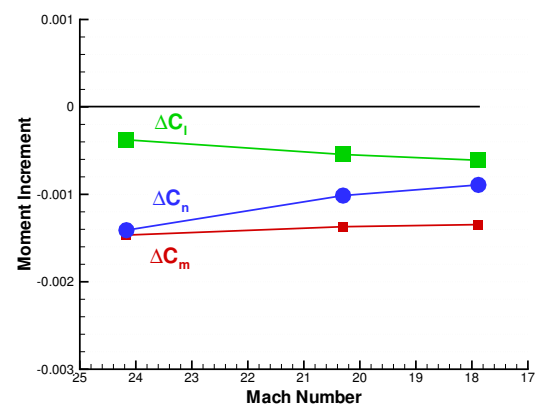

(b) Delta moment coefficients

Figure 21. Delta aerodynamic coefficients for missing RCC panels $6+7$ for range of Mach numbers at $\alpha=40^{\circ}$

panel damage scenarios were consistent with the wind tunnel results. The flow field analysis from these computations clearly indicates that when the windward flow is diverted by WLE damage, the flow field on the leeside of the vehicle is disturbed in a way that is consistent with the increased heating patterns observed during the STS-107 flight. The aerodynamic results from both computation and wind tunnel demonstrate that as more material (i.e., surface area) is removed from the WLE, all of the delta moments trend to more negative values. This is counter to the trend toward a more positive rolling moment seen later (after EI+600 sec) in the STS-107 flight. These two observations taken together suggest the initial STS-107 aerodynamic increments are consistent with WLE damage. However, an additional damage progression scenario, other than a continuing loss of RCC panel(s), is required to explain the aerodynamic trends later in flight. 
Table 6. Progressive damage at RCC panel 9 configurations and cases

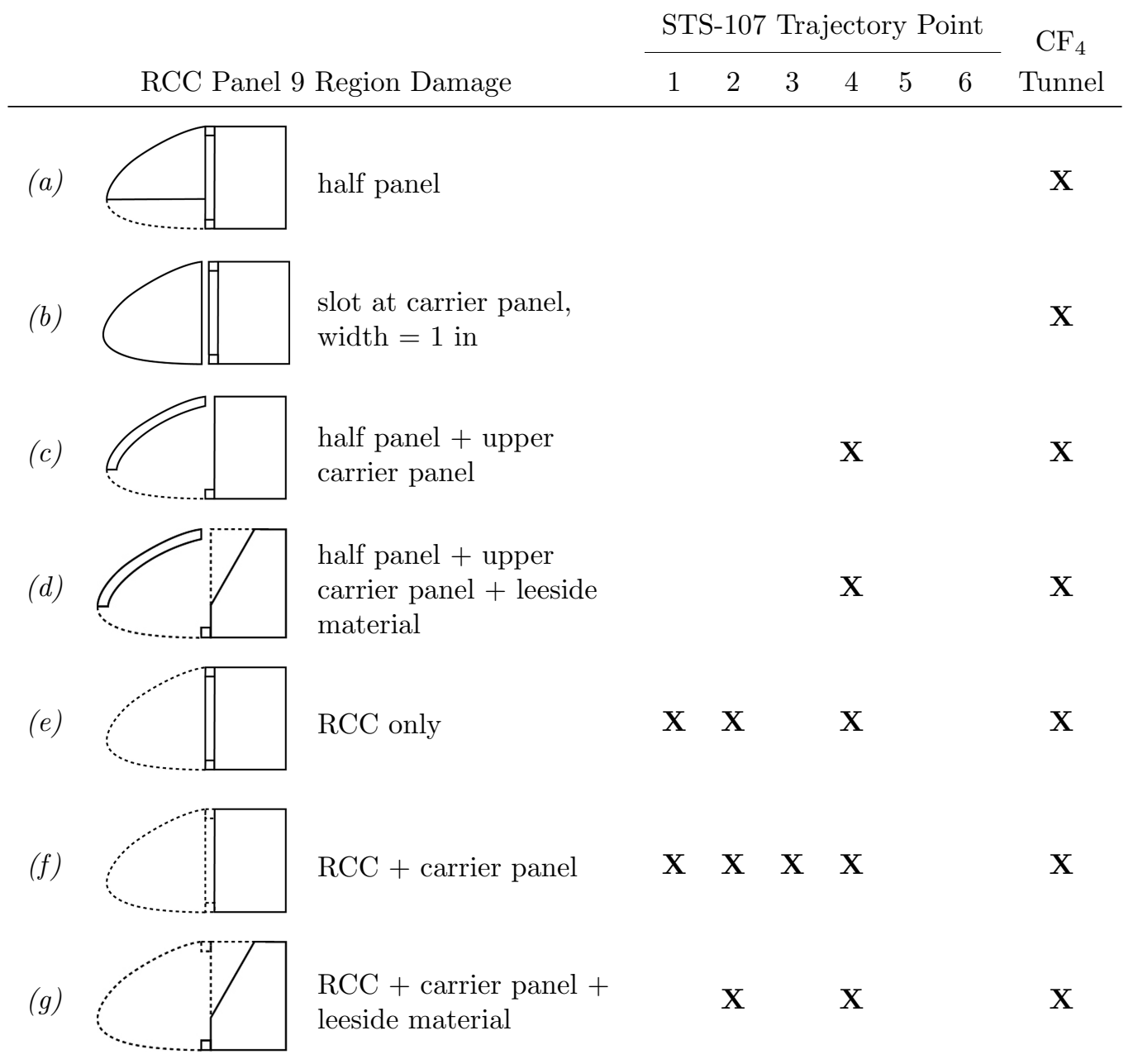

\section{Progressive Damage in Region of RCC Panel 9}

As the investigation progressed, the primary damage location was focused toward RCC panels 8 and 9 . The location of recovered WLE debris and the computational and wind tunnel testing of missing full RCC panel(s) had eliminated from consideration a progression of damage that included RCC panels "zippering" off. The WLE hardware recovered from Columbia suggested that, at least initially, the damage was not as extensive as a full RCC panel missing. These observations led to consideration of a damage progression that started with a relatively small change to an RCC panel, expanded to include a full RCC panel missing and a spar breach, and then removal of material behind the WLE spar. In order to assess the delta aerodynamics of this type of progression, a series of damage scenario configurations was developed with damages increasing in severity in the region of RCC panel 9.

Seven damage scenarios were studied. Representative cross-sections of the wing in the region of panel 9 and the flow conditions computed are given in Table 6. Configurations $(a)-(d)$ are partial damages to RCC panel 9, and $(e)-(g)$ correspond to full RCC panel 9 missing configurations. Configuration $(a)$ is the lower half of RCC panel 9 missing and is the same configuration as tested in the $\mathrm{CF}_{4}$ tunnel. Configuration (b) has a 1.0 inch wide slot from windward to leeside, at the front edge of the upper and lower carrier panels. Configuration $(c)$ is the lower half panel 9 missing with an internal cavity carved out to more closely model the remaining upper RCC shell and the upper carrier panel $\left(\sim 190 \mathrm{in}^{2}\right)$ removed to create a flow path from windward to leeside. This geometry is repeated in damage $(d)$, with an additional $\sim 810$ $i n^{2}$ of leeside material removed aft and inboard of the upper carrier panel, for a total leeside exit area of $\sim 1000 \mathrm{in}^{2}$. The additional material was removed in such a way to create a channel to direct the flow 
toward the vertical tail. The full panel missing configurations, $(e)$ and $(f)$, include RCC panel 9 missing and RCC panel 9 and upper and lower carrier panels missing; configuration $(f)$ was examined earlier in the section on missing full RCC panels. Configuration $(g)$ has the same leeside damage as in $(d)$, and the full RCC panel removed. Both damages $(d)$ and $(g)$ were created to direct as much mass flow as possible toward the OMS pod and vertical tail, to determine if it was possible to generate the positive delta rolling moment observed in flight.

The delta rolling and yawing moments for FELISA cases with progressive damage in the RCC panel 9 region, at flight (CFD condition 4) and $\mathrm{CF}_{4}$ conditions, are shown in Fig. 22. Note that in order to focus on providing a plausible progression of damage that correlates with the STS-107 flight reconstruction, only the delta rolling and yawing moments will be presented for the remainder of the damage configurations. The half panel 9 geometry $(a)$ gives a very small increment in rolling (positive) and yawing (negative) moments, as no windward flow is diverted to the leeside. The delta aerodynamics for the one inch wide slot at RCC panel 9, (b), are essentially zero. Opening a larger flow path by re-

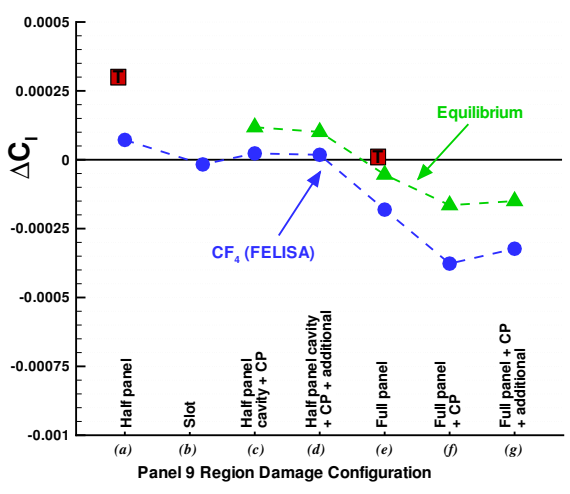

(a) Delta rolling moment

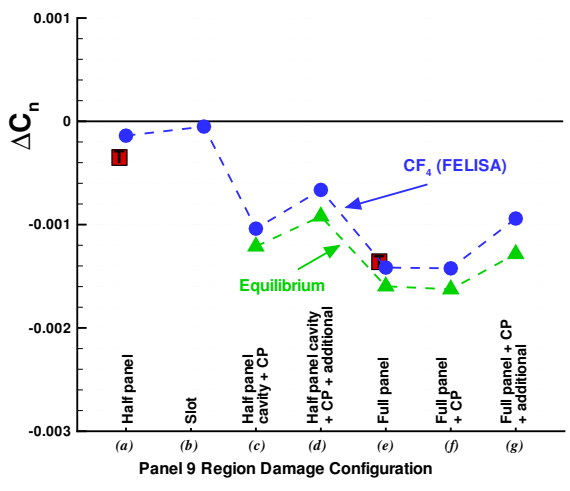

(b) Delta yawing moment

Figure 22. Delta rolling and yawing moments for partial panel 9 damage progression configurations, Felisa equilibrium (CFD Condition 2), Felisa $\mathbf{C F}_{4}$, and $\mathbf{C F}_{4}$ tunnel

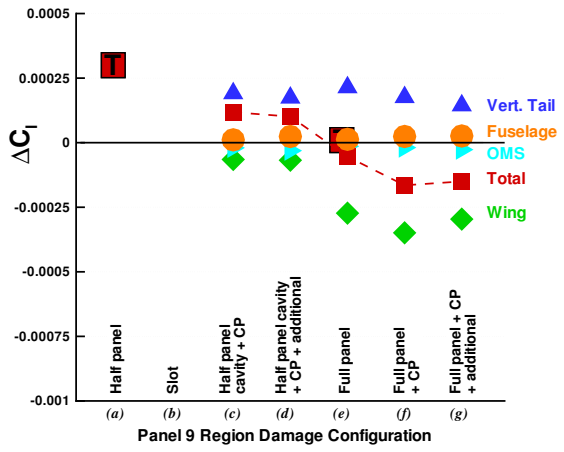

(a) Delta rolling moment, flight

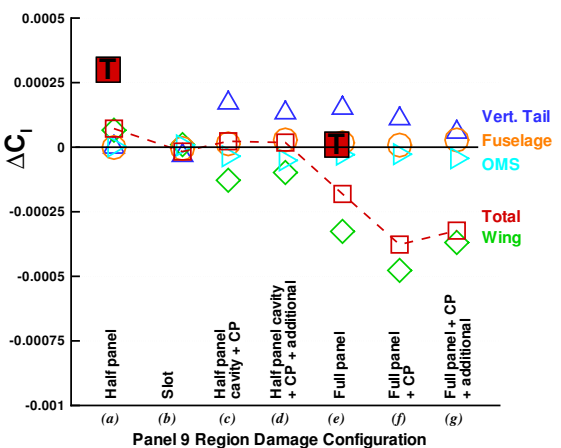

(c) Delta rolling moment, $\mathrm{CF}_{4}$

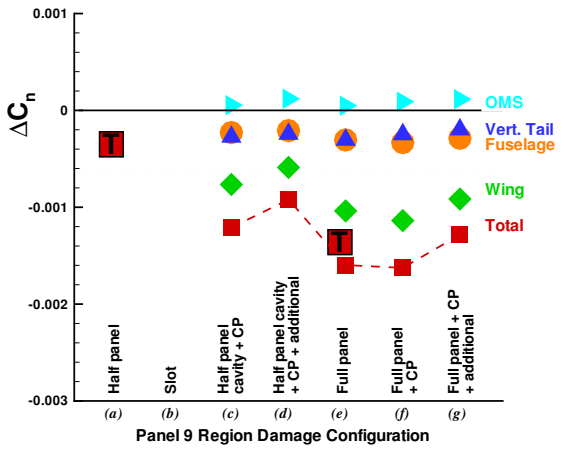

(b) Delta yawing moment, flight

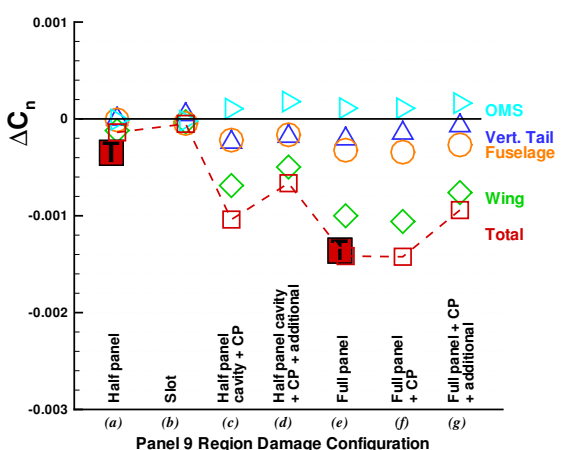

(d) Delta yawing moment, $\mathrm{CF}_{4}$

Figure 23. Component breakdown of delta rolling and yawing moments for partial panel 9 damage progression configurations, FELISA equilibrium (CFD Condition 2), FELISA $\mathbf{C F}_{4}$, and $\mathbf{C F}_{4}$ tunnel

moving the whole upper

carrier panel $9\left(\sim 190 \mathrm{in}^{2}\right)$, configuration $(c)$, does not change $\Delta C_{l}$ and significantly shifts the yawing moment to a more negative value. When the size of the opening on the leeside is increased to $\sim 1000 \mathrm{in}^{2}$ (configuration 
$(d)$ ), there is little change in the delta rolling moment, and a small increase in $\Delta C_{n}$. For the full panel out cases, where more WLE material is removed from $(e)$ to $(f), \Delta C_{l}$ becomes more negative while $\Delta C_{n}$ stays constant. When additional leeside material is removed as in configuration $(g), \Delta C_{n}$ becomes less negative, and $\Delta C_{l}$ remains unchanged. The $\mathrm{CF}_{4}$ computations show the same trends as flight, with $\Delta C_{l}$ lower than flight and $\Delta C_{n}$ higher, consistent with earlier observations.

The component breakdown of the contributions to the delta aerodynamic moments is shown in Fig. 23 for flight (CFD Condition 4) and $\mathrm{CF}_{4}$ tunnel conditions. (Refer to Fig. 12 for the component definition). The contributions from the OMS pod and the side fuselage are small. The vertical tail gives a consistently positive $\Delta C_{l}$ contribution, which is offset to some degree by the wing. The half panel cases $((c)$ and $(d))$ have only a small contribution from the wing, and thus a positive rolling moment. The full panel cases $((e)$ $(g)$ ) have larger contributions from the wing, resulting in a slightly negative rolling moment. The OMS pod, vertical tail, and fuselage give relatively consistent contributions to $\Delta C_{n}$ for all half panel and full panel cases. The variation in $\Delta C_{n}$ is due to the wing contribution. This analysis of component contributions to the total delta aerodynamics shows that a large positive roll does not come from the flow over the vertical tail, even when significant flow is directed toward the vertical tail.

The rolling and yawing moments for a sequence of damage from a half-panel missing to a half-panel and upper carrier panel missing to a full panel missing (configurations $(a)$ to $(c)$ to $(e))$ are shown in Fig. 24 with the reconstructed aerodynamics from Fig. 1] (solid lines). The times assigned to each damage scenario were chosen such that the damage progression was consistent with specific STS107 flight events and with aerodynamic and aerothermodynamic wind tunnel results. The leeside flow fields (not shown) suggest that any of the damage progression configurations that allow flow to the leeside $((c)$ - $(g))$ produce a sig-

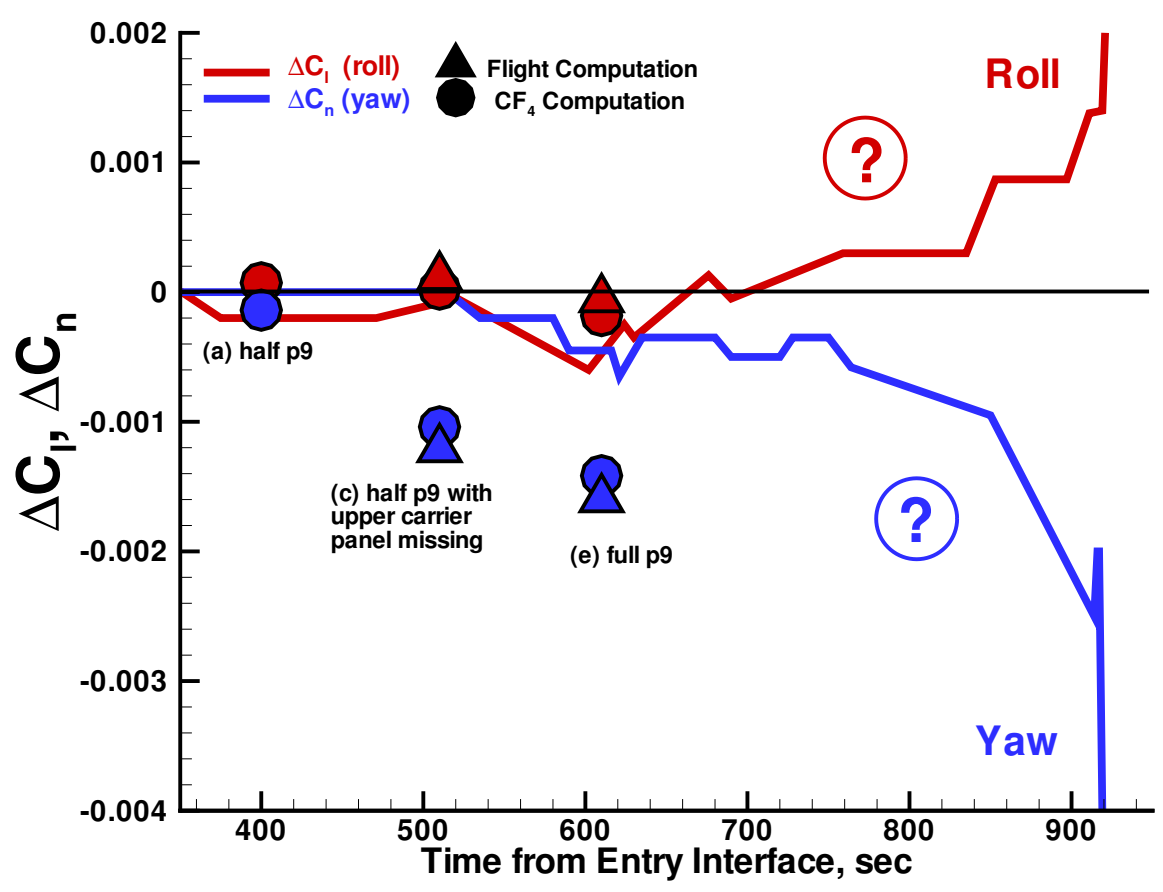

Figure 24. Delta rolling and yawing moments for a progressive damage scenario, through 600 seconds past EI

nificant disturbance on the fuselage side and OMS pod, which would in turn produce higher than normal heating rates. The aerodynamic data, however, indicate that the configurations that produce the most positive delta rolling moment (albeit near zero) are configurations $(c)$ and $(d)$, the ones with only partial damage to the RCC panel and a flow path to the wing leeside. Since partial damage cannot occur after full RCC panel damage, and the reconstructed aerodynamics from Fig. 1 1 show that until 600 seconds past EI the rolling moment was trending negative, the partial panel damage must have occurred early in the flight. The current set of damage scenarios did not produce a large positive rolling moment increment as observed late flight $(\mathrm{EI}+800 \mathrm{sec})$. It is clear that progressively damaging a particular RCC panel does not produce the steady increasing trend in rolling moment increment seen in flight. This suggests that, in addition to the WLE damage, there must be another type of damage that would explain the trend reversal in the delta rolling moment. 
Table 7. Windward surface deformation configurations and cases

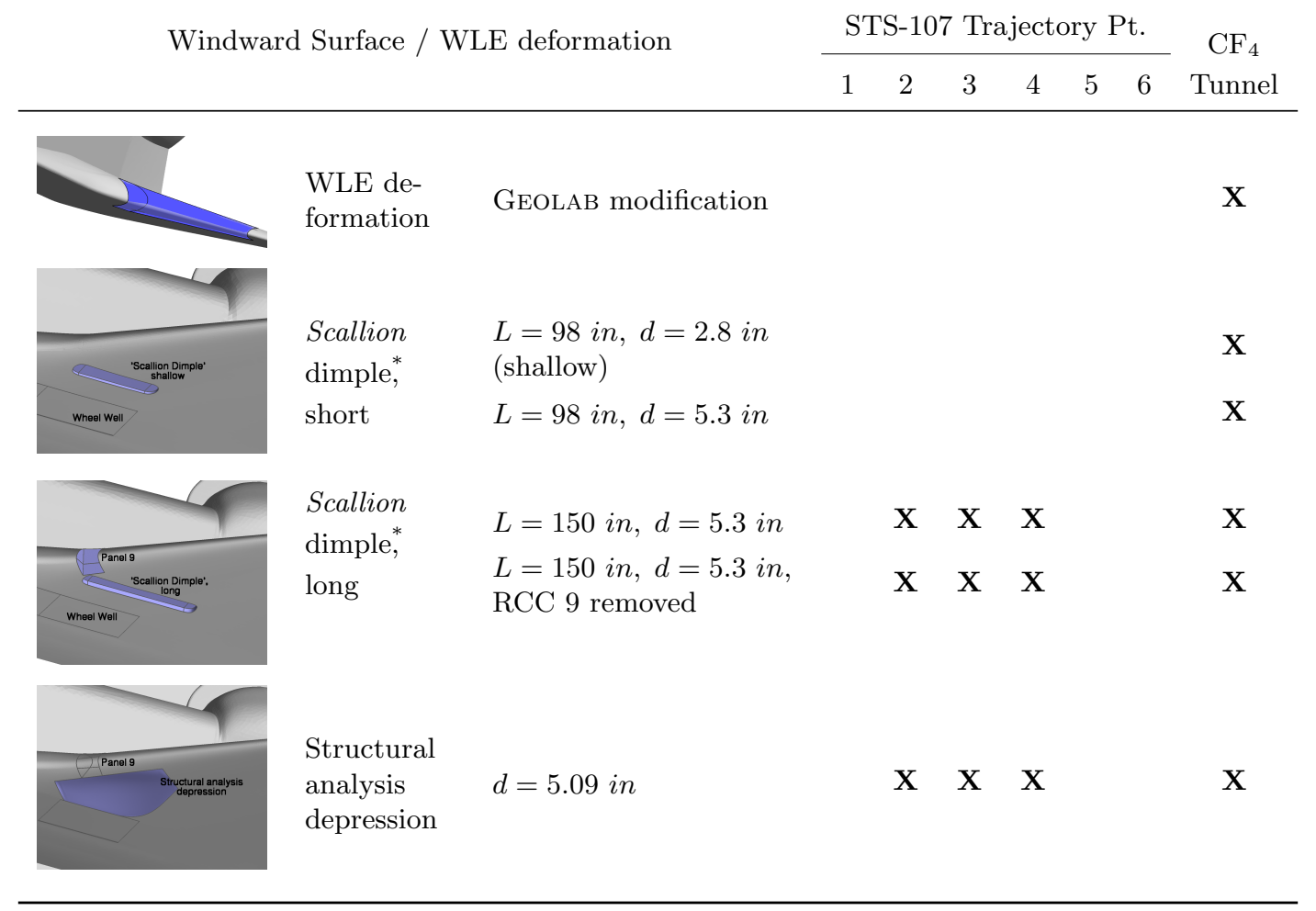

${ }^{*}$ A depression created between the 163 and 192 ribs.

\section{Windward Surface Deformation (Depressions and WLE Deformation)}

A final group of computations was conducted to investigate windward surface depressions/dimples in an attempt to model the deformation of the wing surface due to the heating damage to the intermediate wing internal structure. The wing internal structure is shown in Fig. 25, with the region of interest marked. While early wind tunnel tests with shallow open wheel well cavities had indicated that windward surface cavities could produce the positive roll and negative yaw observed late in flight, loss of the wheel well door was ruled out by forensic evidence. Windside depressions, however, are possible from the wing surface dimpling due to failure of the ribs and delamination of the wing honeycomb skin panels.

The configurations modeled with FeLisa are given in Table 7. The WLE deformation geometry was created by rotating upward several of the RCC panels (as highlighted in Table 7), with the most rotation at RCC panel 9. For a clearer view, Fig. 26] shows the rotated panels that are inboard of RCC panel 9 overlaid on the baseline wing. The Scallion dimple configurations are depressions spanning from the 163 rib to the 192 rib, with varying lengths and depths, and with and without RCC panel 9 removed. The intermediate length depressions extend from the WLE to the end of the wheel well, and the long depressions extend aft to the next bulkhead location. Similar configurations (referenced as single wide) were tested in the $\mathrm{CF}_{4}$ tunnel; the depression created in the ceramic model was milled such that the interior edges were rounded, 
as opposed to sharp edges in the FELISA model. The structural analysis group at JSC performed a FEM simulation of the global deformation of the wing, assuming failure and degraded strength of the structure in the intermediate wing box area. Additional engineering calculations were made on the damaged structure to simulate the localize deformation of the wing surface. The structural analysis efforts to understand the wing deformation late in flight are detailed the Aero/Aerothermal/Thermal/Structures Team final report to the CAIB ${ }^{2}$

The delta aerodynamics for the windward damage cases and corresponding $\mathrm{CF}_{4}$ tunnel data are shown in Fig. 27. The WLE deformation case showed zero delta rolling and pitching moments, and a relatively small delta yawing moment. The agreement between the computations and tunnel data for the single wide depressions is good for the delta yawing and pitching moments, but is not as good quantitatively for rolling moment as was the case for other damage configurations evaluated (See Figs. 17 and 22. These computations show the largest positive rolling moment for any of the damage configurations assessed; $\Delta C_{l}$ is positive for all of the depressions considered. The tunnel data showed positive delta

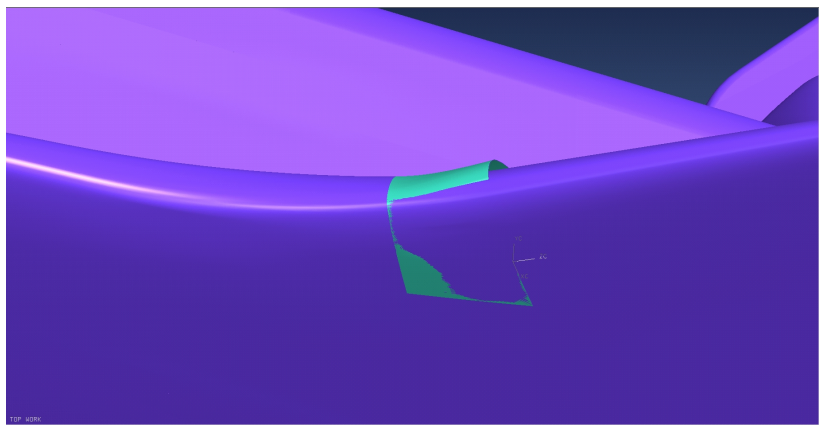

Figure 26. WLE deformation geometry rolling moment only for the longer dimples. This discrepancy is likely due to a combination of geometry differences (particularly the contoured back wall of the depression for the wind tunnel model) and a strong viscous component to this cavity-like flow. The structural analysis configuration shows a smaller, positive $\Delta C_{l}$, and a very small yawing moment increment. This is to be expected, in part because of the more gentle sloping of the structural analysis depression.

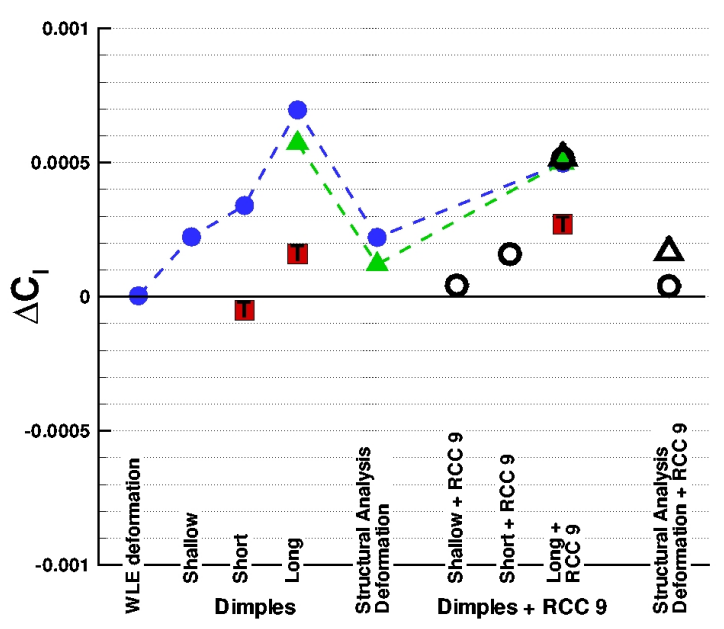

(a) Delta rolling moment

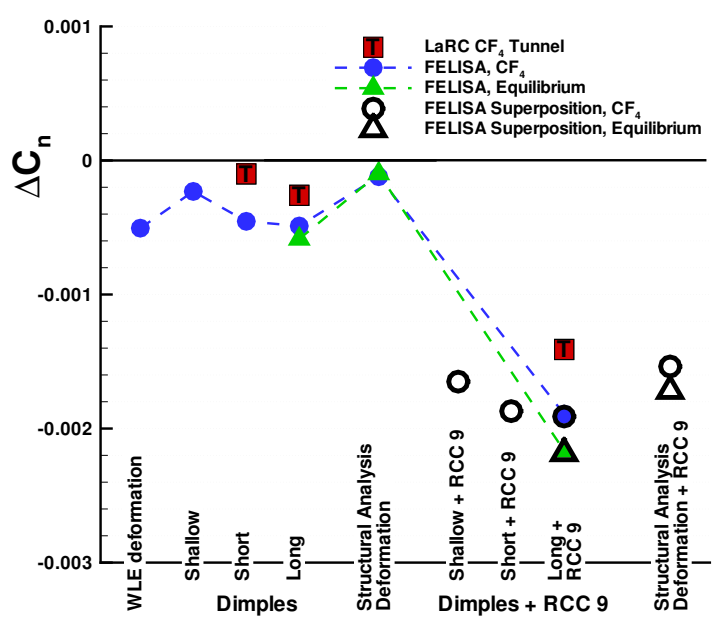

(b) Delta yawing moment

Figure 27. Delta rolling and yawing moments for windward surface deformation configurations, FELISA equilibrium (CFD Condition 4), FELISA $\mathbf{C F}_{4}$, and $\mathrm{CF}_{4}$ tunnel

In addition to the computed and measured delta aerodynamics, Fig. 27 shows estimates, using simple superposition, of the delta aerodynamics for the cases where the windward surface damage is combined with a missing RCC panel. The superposition values (open symbols) compare well with the computed values for the longer, single width depression combined with missing RCC panel 9, and indicate that the postulated structural damage would produce the positive roll and negative yaw that was seen in flight.

Overall, the delta aerodynamics computed with FELISA for windward surface damage configurations compare well with the wind tunnel data. The delta aerodynamics for gradual windward surface deformation created by progressive internal structural damage is consistent with the steady increase in rolling and yawing moment increments occurring late in the flight. 


\section{E. Final Scenario}

The aerodynamics for the various damage scenarios are put together to show a plausible progression of damage that produces delta aerodynamics consistent with the flight delta aerodynamics. A consistent damage progression is developed by including the delta aerodynamics from selected windward surface deformation configurations in Fig. 24. The delta aerodynamics for the final damage progression scenario developed utilizing the FeLISA computations is shown in Figure 28. On entry, there was only minor damage in the RCC panel 9 region. This damage grew until around 500 seconds after EI, when a hole approximately the size of an upper carrier panel began to channel flow to the vehicle leeside. By 600 seconds past EI, the entire RCC panel was missing, and structural deformation of the wing surface began. As the internal structure degraded, and the deformation to the windside surface of the vehicle increased, the trend in rolling moment reverses to positive. Near 900 seconds past EI, something catastrophic occurred, overwhelming the control system. While the specific FELISA configurations focus on the panel 9 region, the results would have been similar for neighboring panels. (Note that the final scenario developed by the $\mathrm{CAIB}^{22}{ }^{23}$ focuses on the panel 8 region, primarily due to forensic evidence.)

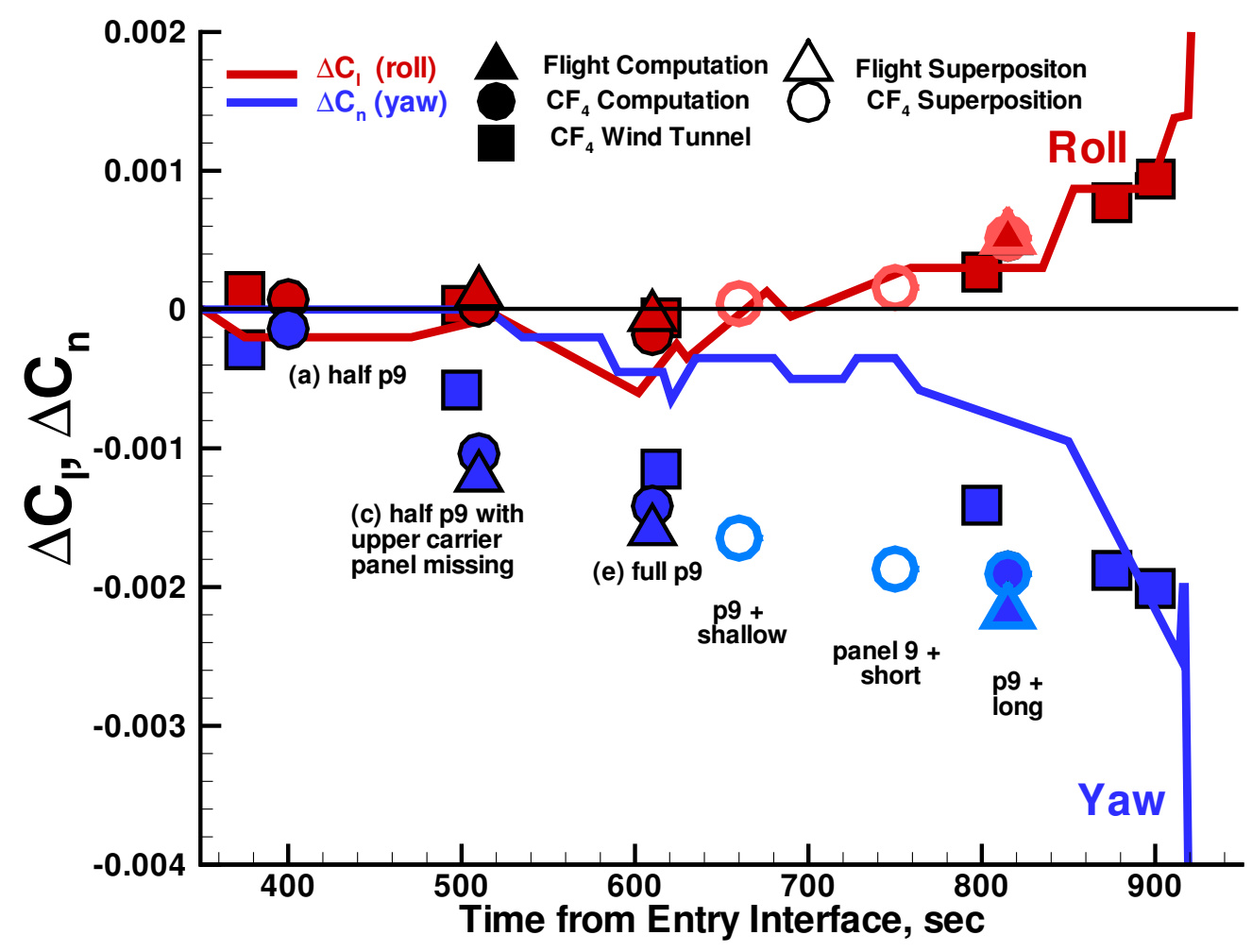

Figure 28. Delta rolling and yawing moments for a progressive damage scenario

\section{Concluding Remarks}

Inviscid computations for a wide range of Shuttle Orbiter damage scenarios were performed at flight and wind tunnel conditions. These predictions of aerodynamic characteristics for various changes to the wing leading edge and windside surface played an important role in understanding Columbia's tragic reentry. Early computations utilizing the rapid modeling and solution turn-around of FeLISA provided the first evidence to support the theory that a portion of the wing leading edge had disintegrated, and led to this scenario being evaluated in the wind tunnel sooner than had been planned. The computed delta aerodynamics gave strong support to the wind tunnel data. Computations at flight and $\mathrm{CF}_{4}$ conditions 
yielded consistent trends, confirming that the $\mathrm{CF}_{4}$ tunnel could simulate hypersonic / hypervelocity flight trends. The correlation between the computations and the wind tunnel measurements gave confidence that very small delta aerodynamics can be computed with FeLISA and measured in carefully run wind tunnel tests. The computations added to the wind tunnel data by localizing aerodynamic effects and visualizing surface flow features. By matching the aerodynamics from selected damage scenarios to the reconstructed flight aerodynamics, a progression of damage that is consistent with the flight data, debris forensics, and wind tunnel data was developed.

\section{Acknowledgments}

This work was performed under the umbrella of the Columbia Accident Investigation Board and the NASA Accident Investigation Team, as a part of the Aerodynamics Team under the direction of Steve Labbe, JSC. The authors interacted extensively with the External Aerothermodynamics Team, led by Chuck Campbell, JSC. The authors wish to thank Greg Brauckmann and Bill Scallion who performed all of the aerodynamic testing in the $\mathrm{CF}_{4}$ and Mach 6 Air facilities and provided much insight to the data, Scott Verden and Norma Bean of GEOLAB for developing much of the damage scenario geometry, Bil Kleb, Mike Park, and Bill Jones for their timely application of preliminary mesh adaptation techniques, and Phil Robinson (JSC) for providing the OADB comparisons.

\section{References}

${ }^{1}$ Operational Aerodynamic Design Data Book Configuration at Hypersonic Speeds, STS85-0118-1 CHG 8, Aug. 1996.

${ }^{2}$ Madera, P., Labbe, S., Madden, C., Caram, and Dunham, M., Aero/Aerothermal/Thermal/Structures Team Final Report in support of the Columbia Accident Investigation, NSTS-37398, Aug. 2003.

${ }^{3}$ Miller, C. G., "Langely Hypersonic Aerodynamic/Aerothermodynamic Testing Capabilities - Persent and Future," AIAA Paper 90-1376, Jan 1990.

${ }^{4}$ Brauckmann, G. J., "Experimental Aerodynamic Characteristics of the Shuttle Orbiter for a Range of Damage Scenarios at Hypersonic Flight and Wind Tunnel Conditions," JANNAF 27th Airbreathing Propulsion, Paper 2B-4, Dec 2003.

${ }^{5}$ Brauckmann, G. J. and Scallion, W. I., "Experimental Hypersonic Aerodynamic Characteristics of the Space Shuttle Orbiter for a Range of Damage Scenarios," AIAA Paper 2004-2280, June 2004.

${ }^{6}$ Brauckmann, G. J., Paulson, J. W., and Weilmuenster, K. J., "Experimental and Computational Analysis of Shuttle Orbiter Hypersonic Trim Anomaly," Journal of Spacecraft and Rockets, Vol. 32, No. 5, September-October 1995.

${ }^{7}$ Horvath, T. J., "Experimental Aerothermodynamics in Support of the Columbia Accisdent Investigation," AIAA Paper 2004-1387, January 5-8 2004.

${ }^{8}$ Peiro, J., Peraire, J., and Morgan, K., "FELISA Reference Manual and User's Guide, Volume I," University of Wales/Swansea Report CR/821/94, 1994.

${ }^{9}$ Bibb, K. L., Peraire, J., and Riley, C. J., "Hypersonic Flow Computations on Unstructured Meshes," AIAA Paper 97-0625, Jan. 1997.

${ }^{10}$ Prabhu, R. K., "An Inviscid Computational Study of the Space Shuttle Orbiter and Several Damaged Configuration," NASA/CR 2004-213241, June 2004.

${ }^{11}$ Prabhu, R. K., "Inviscid Flow Computations of Several Aeroshell Configurations for a '07 Mars Lander," NASA/CR 2001-210851, April 2001.

${ }^{12}$ Prabhu, R. K., "Inviscid Flow Computations of Two '07 Mars Lander Aeroshell Configurations Over a Mach Number Range of 2 to 24," NASA/CR 2001-210852, April 2001.

${ }^{13}$ Prabhu, R. K., "An Inviscid Computational Study of an X-33 Configuration at Hypersonic Speeds," NASA/CR 1999209366, 1999.

${ }^{14}$ Prabhu, R. K., "Inviscid Flow Computations of the Orbital Sciences X-34 Over a Mach Number Range of 1.25 to 6.0," NASA/CR 2001-210849, April 2001.

${ }^{15}$ Prabhu, R. K., "Inviscid Flow Computations of the Space Shuttle Orbiter for Mach 10 and 15 and Angle of Attack 40 to 60 Degrees," NASA/CR 2001-211267, Dec. 2001.

${ }^{16}$ Samareh-Abolhassani, J., "GridTool: A Surface Modeling and Grid Generation Tool," Proceedings of the Workshop on Surface Modeling, Grid Generation, and Related Issues in CFD Solutions, NASA CP-3291, May 1995, pp. 821-831.

${ }^{17}$ Jones, W. T., "An Open Framework for Unstructured Grid Generation," AIAA Paper 2002-3192, June 2002.

${ }^{18}$ Jones, W. T., "GridExAn-An Integrated Grid Generation Package for CFD," AIAA Paper 2003-4129, June 2003.

${ }^{19}$ Gnoffo, P. A., Weilmuenster, K. J., and Alter, S. J., "Multiblock Analysis for Shuttle Orbiter Re-entry Heating from Mach 24 to Mach 12," Journal of Spacecraft and Rockets, Vol. 31, No. 3, 1994, pp. 367-377.

${ }^{20}$ Weilmuenster, K. J., Gnoffo, P. A., and Greene, F. A., "Navier-Stokes Simulations of Orbiter Aerodynamic Characteristics Including Pitch Trim and Bodyflap," Journal of Spacecraft and Rockets, Vol. 31, No. 3, 1994, pp. 355-366.

${ }^{21}$ DeVenezia, J., Wang, K. C., and Caram, J., "Space shuttle Orbiter Wing Leading Edge Heating Predictions and Measurements," Orbiter Experiments (OEX) Aerothermodynamics Symposium, NASA CP-2283, April 1995, pp. 741-809.

${ }^{22}$ Columbia Accident Investigation Board, Report Volume I, Aug. 2003.

${ }^{23}$ Columbia Accident Investigation Board, Report Volume II, Aug. 2003. 